Article

\title{
Integrated Algorithm for Selecting the Location and Control of Energy Storage Units to Improve the Voltage Level in Distribution Grids
}

\author{
Agata Szultka ${ }^{1}$, Seweryn Szultka ${ }^{2, *}$, Stanislaw Czapp ${ }^{2} \mathbb{1}$, Zbigniew Lubosny ${ }^{2}$ and \\ Robert Malkowski ${ }^{2}$ (D) \\ 1 Energa-Operator SA, Marynarki Polskiej 130, PL-80-557 Gdańsk, Poland; agata.szultka@energa-operator.pl \\ 2 Faculty of Electrical and Control Engineering, Gdańsk University of Technology, Narutowicza 11/12, \\ PL-80-233 Gdańsk, Poland; stanislaw.czapp@pg.edu.pl (S.C.); zbigniew.lubosny@pg.edu.pl (Z.L.); \\ robert.malkowski@pg.edu.pl (R.M.) \\ * Correspondence: seweryn.szultka@pg.edu.pl
}

Received: 11 November 2020; Accepted: 18 December 2020; Published: 19 December 2020

\begin{abstract}
This paper refers to the issue that mainly appears in distribution grids, where renewable energy sources (RES) are widely installed. In such grids, one of the main problems is the coordination of energy production time with demand time, especially if photovoltaic energy sources are present. To face this problem, battery energy storage units (ESU) can be installed. In recent years, more and more attention has been paid to optimizing the use of ESU. This paper contains a simple description of available solutions for the application of ESU as well as an original proposal for selecting the optimal location and control of ESU. The ESU selection method is based on the use of a genetic algorithm and the ESU control method utilizes the fuzzy logic. The combination of the aforementioned methods/algorithms of ESU application is named an integrated algorithm. The performance of the proposed algorithm was validated by multivariate computer simulations with the use of the real low-voltage grid model. The DIgSILENT PowerFactory environment was employed to develop the simulation model of the integrated algorithm. The proposal was utilized to improve the voltage level in the distribution grid and to install the optimal number of ESU. Based on daily load variations for selected load profiles, it was shown that after the ESU application the voltage deviations in the analyzed network were significantly limited. Moreover, the analysis proves that both the location of ESU in the grid and the control of their active and reactive power are important from the point of view of reducing overall costs.
\end{abstract}

Keywords: energy storage units; genetic algorithm; fuzzy logic; low-voltage grid analysis

\section{Introduction}

Distribution grid operators face numerous challenges. One of them is installing renewable energy sources (RES) deep inside the distribution grid, which in recent years has been the cause of problems with failure to meet the required voltage value [1]. Solar panels (which are an example of RES) appear more and more among prosumers as micro-sources. The greatest production of power by photovoltaic (PV) sources often occurs during the period of low load of the grid. This phenomenon is the cause of voltage problems, especially in low-voltage (LV) grids. In consequence, the power produced by RES cannot be fed into the grid from time to time due to the voltage value that exceeds the permissible upper limit in the connection node.

In order to eliminate the above-mentioned problems, the grids can be rebuilt. It can be done by the increase of the cross-sectional area of the low-voltage power lines conductors-such a method reduces 
the unit resistance of the line and, hence, reduces values of the voltage drop/deviation in the grid. Another method is decreasing the length of the low-voltage power lines-it decreases their impedance. However, this method requires the use of more transformer substations in order to localize them as close as possible to the prosumers. In [2] the search for optimal radial topology is presented that minimizes the total length of the distribution lines and improves load balancing. However, this solution is time-consuming, expensive, and does not rule out the occurrence of further problems related to the installation of more RES. The paper [3] shows the possibility of using an auxiliary voltage source installed in series in the power line. However, this solution can be used only for a certain group of cases due to the limited possibility of controlling the voltage level. Another solution is the use of energy storage units (ESU) that manage the flow of active and reactive power in the power grid [4].

ESU, through the possibility of storing energy in them, can contribute to the elimination of the negative impact of stochastic variability of power generated by RES [5-7]. As a consequence, they can reduce voltage problems by balancing the active and reactive power production and demand, as well as decrease the grid load peaks, while reducing power losses and eliminating overload of transmission elements [8,9]. However, the cost associated with the installation of ESU remains high. Therefore, it is rational to focus on their effective utilization, i.e., meeting the set goals at the lowest possible cost of installation. The factor influencing the effective use of ESU is the appropriate selection of their rated power, capacity, and location in the grid [10]. Another important element of the optimization is proper control of stored energy, which allows for the efficient operation of ESU through appropriate management of the generated/consumed active and reactive power [11].

The location of ESU in the distribution grid is a problem considered in many publications. The following methods are used to select the location of ESU. Analytical methods (AM) are often applied but they do not use advanced optimization tools-they operate very well when the optimization does not contain many variables. Most often, due to the problem complexity, which may be to find the location of the energy storage unit in the grid, the analytical methods are only used for determining the size of the technical parameters of ESU, not the location [12-15]. This is because in the optimization process of a complex issue (such as optimization of the location of ESU in the grid) the analytical method will achieve a solution for the local optimum, not reaching the global optimum. Mathematical programming (MP) uses mathematical models, in particular optimization models, to facilitate decision making. This method allows to find the optimal solution for simplified models. In order to indicate the location and selection parameters of ESU in the power grid, the following cases of the mathematical programming are used. Linear programming (LP) is the most effective method of searching for the global maximum, where the model and constraints are linear. The LP method is used in [16], where the number and size of the ESU are optimized by using the criterion of keeping the voltage in the right range at nodes in the power grid. In [17], in the optimization process, the cost criterion is used, the components of which are defined linearly. Mix-integer linear programming is used for selecting the size and location of energy storage units in [18,19]. Semidefine programming (SDP) is one of the convex optimization methods (the function defined by the user which will be minimized or maximized) to the intersection of the cone of positive semidefined matrices with the affine space, i.e., spectrum. SDP is used in [20] for the appropriate placement of ESU in the grid for specific ESU costs. Another example of this method use is published in [21]. In [22], mix-integer semidefine programming is used. Programming the second-order cone programming (SOCP) is a convex optimization in which a linear function is minimized at the intersection of an affine linear manifold with the product second-order Cartesian cones. This method is used in [23] in order to find the location and size of ESU where the target is ensuring the required voltage level in the power grid, reduction of losses and costs related to the purchase of external energy networks, with the lowest possible investment outlay for ESU. Examples of the application of the SOCP method can be found in [24,25]. Dynamic programming (DP) is simplifying a complicated problem by breaking it down into simpler partial problems in relation to several parameters. If subordinate problems can be recursively implemented in bigger problems, also using dynamic programming methods, then there is a dependency between the value of the parent 
problem and the values of the subproblems. This method is used in [26] to minimize the grid operation costs as well as investment costs for ESU. In the field of the mathematical optimization, stochastic programming (SP) is a framework for modeling the optimization problems that come with uncertainty. The goal is to find a solution that is possible for all or nearly all possible data cases and maximizes the functions of decision and random variables. The SP method is used to determine the location and size of ESU in the power grid, what is presented in [27]. Another method of searching for the appropriate location of ESU in the power grid is an exhaustive search (ES), which is generally used in discrete problem cases. A proper solution is sought in the entire field of solutions. Unfortunately, the search is time consuming because every combination has to be checked. This method applies only in cases where the domain solutions to the problem are small. The exhaustive search is presented in [28] in the process of selection of the smallest possible ESU to obtain the required voltage in the grid. Lately, heuristic methods (HM) have also been used to search for the location of ESU. HM use the imitation of phenomena occurring in nature, i.e., adaptation of the population to the environment, finding food by swarms of individuals in order to find the optimal solution. They do not guarantee finding a global optimal solution, but allow to get a faster solution close to the optimal one in the entire searched space. Moreover, the risk of 'stopping' the method on local optimum does not exist here, as in the case of analytical methods. Heuristic methods are used for related issues with the location of ESU in the grid as well. Among them, the following can be distinguished: genetic algorithms (GA) applied in [29-31], nondominated genetic algorithm (NSGA II) for multicriteria optimization used in [32]; particle swarm optimization (PSO) analyzed in [33]; artificial bee colony (ABC) considered in [34]; bat algorithm (BA) used in $[35,36]$ as well as simulated annealing (SA) probabilistic technique of approximating the global optimum of a given function. The latter is often used when the search space is discrete [37]. These algorithms are sometimes a symbiosis of various heuristic methods, e.g., in [38] the method using genetic algorithms with the particle swarm method. Clustering methods (CM) are utilized very rarely for optimization of the location of ESU. The CM are applied to select the location of ESU [39], in which they are used for identifying groups of similar objects in multidimensional data sets. They complement other methods by narrowing down the field of research. The search assumed the installation of only one energy storage unit-the method allows to determine the approximate solution in which a given location criterion and knowledge about the available grid operation are considered. The following general principles/criteria can be included to reach the voltage at the required level [40]: location of ESU in nodes where there is the lowest voltage level, location of ESU in nodes that are far from the point of the mains supply (high impedance of the power line), location of ESU in nodes to which large loads are connected. Another criterion is maximizing energy production from renewable sources-it requires the location of the ESU at a short distance in the sense of impedance values, from the power source. In some cases, to decrease the current in the overloaded power line (especially during the peak load), the use of ESU at the end of the transmission element (in the context of power flow) is considered. The expert method and other methods mentioned above for voltage improvement may be based on the voltage sensitivity matrix specified for individual nodes in the grid [41,42]. In the process of ESU selection, the matrix of losses in individual grid elements is also used, which provides information on the features of the analyzed grid [43].

Regarding the ESU operation control, the following methods are distinguished: simple controller (SC), which is most often based on using the PID controller. The PID controller operates in a loop (feedback), where the error value is calculated. The purpose of the regulation is to minimize the error value by proper feeding of the signal to the input of the regulated object. In $[44,45]$ the voltage deviation in a network node is minimized. In [46] the authors use the PID control of the ESU cooperating with the wind farm to minimize power fluctuations output of wind farms as well as for grid frequency control. The simple controller operates quite well where there is one control object. On the other hand, if the error value is influenced not only by one object (in this case a lot of ESU in the power grid influence the voltage level), the control process is extended in time. Another method is to use a fuzzy controller (FC). It imitates human skills to solve complex problems in a simple way. Fuzzy control is 
an alternative to classic control, especially where absolute precision is not required, but the simplicity of the solutions and speed of operation are key factors. Examples of the application of fuzzy regulation for ESU control is given in [47,48]. The next method is the use of artificial neural network controller (ANNC). ANNC is made up of elements called neurons, programmed to form a response to the external excitation signal. The neuron is the basic network building block. Its name comes from its biological counterpart, but in this case, the neuron is modeled by a small segment of computer code, called a perceptron. Several neurons stay connected together in a network that learns during the training process how to respond to the excitation signal. It is an iterative process-it involves giving a signal and comparing the response with the reference to make a correction. The advantage of this solution is the possibility of an ongoing 'learning' controller in the context of the decisions made, even if the working environment changes. An example of the use of neural networks for control of ESU for cooperation with RES is presented in [47]. The use of ANNC in the ESU control process turns out to be particularly useful when, for example, load profiles change, but the disadvantage of the solution is the time needed by the controller to 'learn'. It is possible to apply the mathematical programming method-such a method is used in [49]. Stochastic dynamic programming is applied to mitigate fluctuations in the power generated by the wind farm taking into account the ageing process of the ESU depending on the number of cycles performed and the depth of discharge. It is a technique of modeling and solving decision-making problems under conditions of uncertainty. Stochastic dynamic programming, closely related to stochastic programming and programming dynamic, represents the investigated problem in the form of the Bellman equation. The aim is to develop a policy to define the optimal performance in the face of uncertainty. The control of the ESU can also be implemented using heuristic methods, i.e., in [50] the control of the network operation is realized using nondominated sorting genetic algorithm.

The above-mentioned works and papers did not involve the integrated optimization of the location of ESU and the optimization of the parameters of energy storage controllers based on a specific configuration. The goal of the authors is to create an algorithm that optimizes not only the location of ESU but also the operation of ESU in various configurations, taking into account the control of active and reactive power to be generated by ESU. The proposed solution is universal and precise for the application in the process of selection and control of the ESU, in order to obtain the desired voltage levels in low-voltage power grids. With the foregoing in mind, the optimization referred to the ESU are based mainly on the genetic algorithm implemented in PowerFactory software [51,52]. The paper also includes the development of a multiparameter energy storage controller. The controller is based on fuzzy logic, the parameters of which are matched for each location configuration. An evolutionary algorithm is used to select the appropriate parameters of the controller.

\section{Materials and Methods}

\subsection{Description of the Proposed Algorithm for Selection of ESU Location}

The selection of the location of ESU is based on the maximization of the objective (fitness) function $f$ (further described by the (5)). In the genetic algorithm, the best-adapted individuals achieve the highest values of the objective function. Optimization is performed based on daily load variations, where the change is modeled with a $\mathrm{d} t=15$-min time step, hence number of steps (analysis period) is equal to $T=96$ (per $24 \mathrm{~h}$ ).

The population $\mathbf{P}$ was assumed to consist of $k_{\max }$ individuals $(k$ is the number of successive individuals in the population; for all symbols see Appendix A). Each individual consists of one chromosome with $n$-genes. The representing matrix of the $\mathbf{P}$ population is described as follows:

$$
\mathbf{P}=\left[\begin{array}{ccc}
i_{1,1} & \ldots & i_{1, n} \\
\ldots & \ldots & \ldots \\
i_{k \_ \text {max }, 1} & \ldots & i_{k_{-} \max , n}
\end{array}\right]
$$


The gene $i$, where $i=1 \ldots n$ corresponds to a specific grid node in which it is possible to install an energy storage unit. Values that can be assigned to genes are natural numbers and correspond to a defined type of ESU. The objective function $f$ is calculated for each individual from the whole population - the group of results $\mathbf{F}_{t}$ are described by:

$$
\mathbf{F}_{t}=\left[\begin{array}{c}
f_{1} \\
\cdots \\
f_{k \_\max }
\end{array}\right]
$$

Selection of ESU is carried out using the so-called roulette method that results in a random selection of individuals taking into account the value of their objective function. Individuals with the highest function of adaptation have the best chance of contributing to the creation of a new generations. New individuals are created using genetic operators, such as crossing and mutation. In each step the new generation is verified, i.e., individuals are discarded after sorting with the lowest degree of adaptation.

The degree of an individual's adaptation is determined by the value of the function $\mathbf{F}$. It can be represented as the sum of the $\mathbf{F}_{t}$ calculated after each power flow, for discrete time $t=\langle 1, T\rangle$ :

$$
\mathbf{F}=\sum_{t=1}^{T} \mathbf{F}_{t}
$$

The condition for stopping the algorithm is reaching the maximum generation number $d_{\max }$. The best individual, whose objective function achieved the highest value of $f_{\max }$, is selected from all populations occurring throughout the reproductive period:

$$
f_{\max }=\max \left[\begin{array}{ccc}
f_{1,1} & \ldots & f_{k_{\_} \max , 1} \\
\ldots & \ldots & \ldots \\
f_{1, d \_\max } & \cdots & f_{k_{-} \max , d_{\_} \max }
\end{array}\right]
$$

After selecting the best individual, gene values in its chromosome are assigned as the final solution. A flow chart of the operation of the described genetic algorithm used for selecting the location of ESU in the grid is shown in Figure 1.

\subsection{The Objective Function}

The practice related to the operation of the distribution grid shows that currently in medium-voltage (MV) and low-voltage (LV) grids the main problems are related to failure to meet the required voltage value and problems with overloading transmission elements. The requirements related to voltage are included as components of the objective function in further consideration. An additional component of the objective function is to reduce active power losses in the grid. These requirements should be met with the lowest possible cost associated with the installation of ESU. The goal of the optimization is maximizing the value of the objective function described by the following formula:

$$
f=C-p_{2}-\sum_{t=1}^{T}\left(p_{1}+p_{3}+p_{4}\right)
$$

where:

$p_{1}$-component responsible for the cost of failure to meet the required level of voltage in the grid $(€)$,

$p_{2}$-component responsible for the cost of installing ESU in the grid $(€)$,

$p_{3}$-component responsible for power losses in the grid $(€)$,

$p_{4}$-component responsible for the cost of overloading the elements of the grid $(€)$, 
C—constant used to take positive value of $f$.

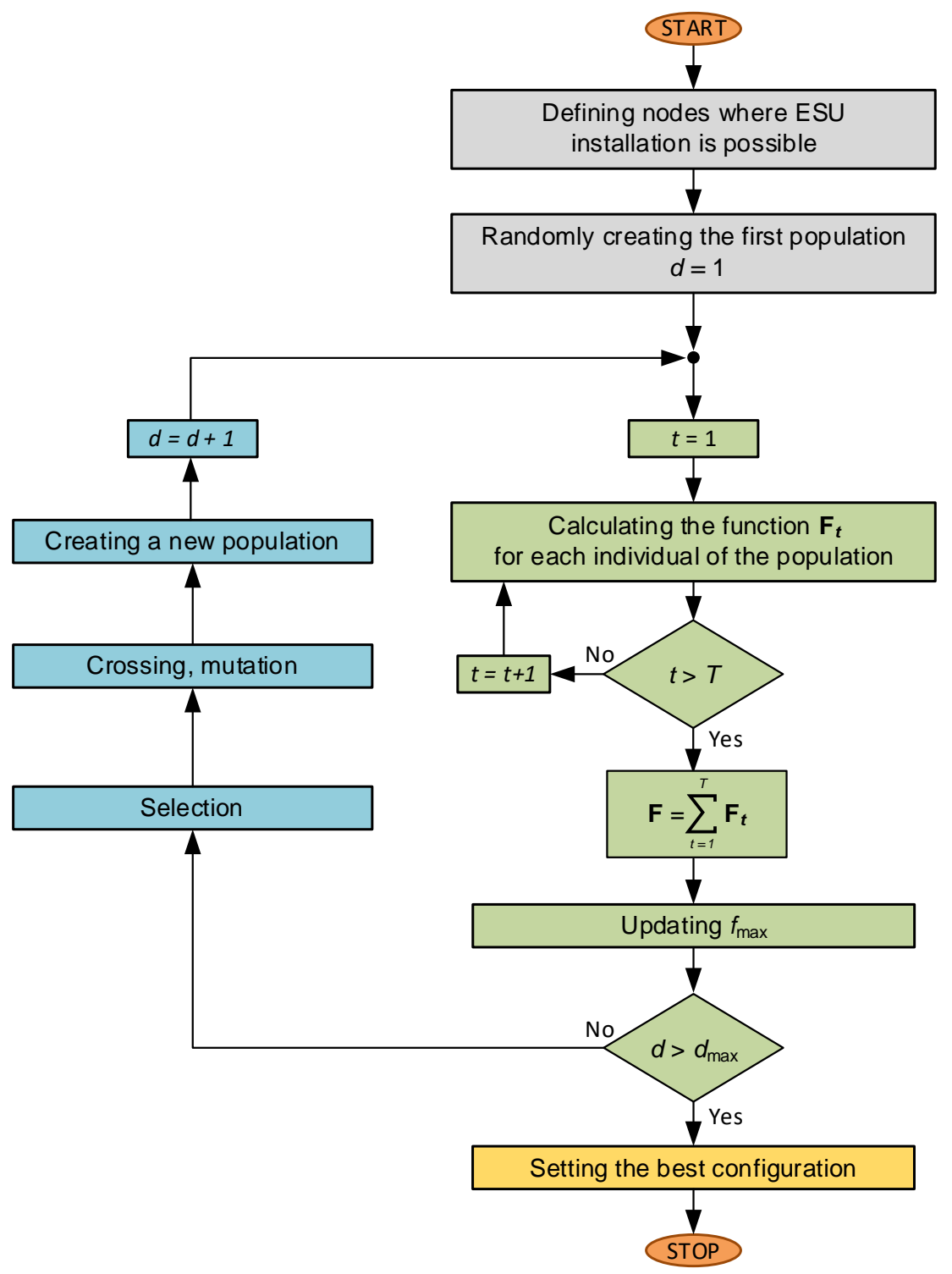

Figure 1. A diagram of the genetic algorithm used to select the location of energy storage units (ESU) in the distribution grid (for symbols see Appendix A).

The value of the objective function (5) is negatively influenced. The costs related to failure to keep the required voltage level in the grid and the related costs with the installation of ESU have to be reduced.

Component of the objective function responsible for the voltage level is described by the formula:

$$
p_{1}=\sum_{n=1}^{N} W_{\mathrm{UT}}
$$

where:

$W_{\mathrm{UT}}-$ cost related to failure to keep the required voltage level in node $n$, $\mathrm{N}$-number of nodes in the grid. 
For example, in the Polish national power system, costs related to failure to meet the corresponding voltage level are divided into three groups. The first group-when the voltage value is within the required range of $V_{\operatorname{minA}}$ and $V_{\operatorname{maxA}}$, the additional cost is zero. The second group-when the voltage falls in the range $\left\langle V_{\min B} ; V_{\min A}>\right.$ or $\left\langle V_{\operatorname{maxA}} ; V_{\operatorname{maxB}}>\right.$, the costs are described by the Formulas (7) and (8):

$$
\begin{aligned}
& W_{\mathrm{UT}}=\left\{\begin{array}{c}
\left(\frac{\Delta V}{\Delta V^{*}}\right)^{2} \cdot A_{\mathrm{t}} \cdot C_{\mathrm{t}}, \text { where } V \epsilon\left\langle V_{\min }, V_{\min \mathrm{A}}\right\rangle\left\langle V_{\max \mathrm{A}}, V_{\operatorname{maxB}}\right\rangle \\
A_{\mathrm{t}} \cdot C_{\mathrm{t}}+b_{\mathrm{rT}} \cdot t_{\mathrm{r}}, \text { where } V \epsilon\left\langle 0, V_{\min \mathrm{B}}\right\rangle\left\langle V_{\operatorname{maxB}}, \infty\right\rangle
\end{array}\right. \\
& \Delta V^{*}=\frac{V_{\min \mathrm{A}}-V_{\min \mathrm{B}}}{V_{\mathrm{n}}}
\end{aligned}
$$

where:

$\Delta V$-voltage deviation from the nominal value,

$A_{\mathrm{t}}$ - energy ( $\mathrm{MWh}$ ) consumed in a given node during the analyzed period,

$C_{\mathrm{t}}$-average price of electric energy. The average price from 2016 was used for the calculations: 39.80 (€/MWh) [53],

$b_{\mathrm{rt}}$-additional fee for failure to meet the required voltage level. In 2016, the fee was: $2.33(€ / \mathrm{h})[53]$,

$t_{\mathrm{r}}$-duration of voltage failure.

Formulas (7) and (8) are also used when voltage $V_{\operatorname{minB}}$ or $V_{\max }$ is exceeded [53,54] (the third group).

The cost of ESU is related to the selection of their appropriate type. Table 1 presents the assumed costs of ESU considered in the further LV grid analysis. The presented parameters of ESU were derived from the Fronius offer in the year 2019. Current parameters of ESU can be found in [55].

Table 1. Technical parameters and the cost of ESU used in the analysis of LV grids.

\begin{tabular}{cccc}
\hline Tray No. & Power $(\mathbf{k W})$ & Capacity $(\mathbf{k W h})$ & Cost $(\boldsymbol{€})$ \\
\hline 1 & 4.0 & 7.5 & 7679.07 \\
2 & 4.8 & 9.0 & 8730.23 \\
3 & 5.6 & 10.5 & 9689.53 \\
4 & 6.4 & 12.0 & $10,644.20$ \\
5 & 8.2 & 13.5 & $11,551.20$ \\
6 & 9.0 & 14.0 & $12,411.60$ \\
\hline
\end{tabular}

The cost of installing ESU is composed of the choice of rated power and capacity of ESU and places of their installation. As the analysis of the grid operation covers 1 day, the cost of installing the ESU in a given node is divided by the total expected period (in days) of the ESU operation (average estimated total time for modern lithium-ion batteries operation is approx. 10 years, i.e., $t_{\mathrm{p}}=365{ }^{*} 10$ ). The total cost (described by the formula (9)) of installing ESU in the grid includes the sum of the costs of all equipment designed for ESU in $N$ nodes:

$$
p_{2}=\sum_{n=1}^{N}\left(\frac{K+W_{\mathrm{n}}}{t_{\mathrm{p}}}\right)
$$

where:

$W_{\mathrm{n}}$ - cost of installing the ESU in node $n$,

$K$ - cost of a given type of ESU,

$t_{\mathrm{p}}$ - expected period of the ESU operation (in days). 
Active power losses $\Delta P$ in the power grid multiplied by the electric power price $C_{t}$ and time $t$ can be directly related to costs. The energy losses are cumulative in a grid consisting of $L$ transmission elements:

$$
p_{3}=\sum_{l=1}^{L} \Delta P_{1} \cdot C_{\mathrm{t}} \cdot \mathrm{d} t
$$

where:

$\Delta P_{1}$-active power losses in the grid element $l_{\mathrm{i}}$,

$L$-number of grid elements,

$\mathrm{d} t$-15-min time step.

Exceeding the permissible long-term temperature for a given type of power cable insulation reduces the designed insulation durability according to exponential dependence described by the Arrhenius curve [56]. This relationship is contained in the $p_{4}$ component, which is described by formulas (11) and (12) and applies to cable lines:

$$
\begin{gathered}
p_{4}=\sum_{l=1}^{L} a \\
a=\left\{\frac{\left[C_{\mathrm{TP}} \cdot l_{c} \cdot\left(1-127768 \mathrm{e}^{\left.-8.715 \frac{L_{\mathrm{o}}}{100 \%}\right)}\right) \cdot t_{\mathrm{i}}\right.}{0, \text { where }\left(L_{\mathrm{oi}}^{\mathrm{T}}<100 \%\right)}, \text { where }\left(L_{\mathrm{Oi}}>100 \%\right)\right.
\end{gathered}
$$

where:

$C_{\mathrm{TP}}$ - unit price of a given type of a cable $(€ / \mathrm{km})$,

$L$-number of grid elements,

$l_{\mathrm{c}}$-cable length $(\mathrm{km})$,

$L_{\mathrm{oi}}$-load in the $i$-th element of the grid (\%),

$T$-number of time steps $(T=96)$,

$t_{\mathrm{i}}$-number of steps (in analysis period) when the $i$-th element of the grid is overloaded,

$a$-auxiliary variable.

\subsection{The Controller of the ESU}

A controller was developed for the proper supply of active and reactive power from the ESU. The scheme of the energy storage control system is shown in Figure 2.

The main criterion for ESU control is the value of voltage $V_{\mathrm{w} \_n}$ at the point of common coupling (PCC) -node $\mathrm{n}$ in Figure 2. It is also possible to measure the voltage on any grid node. In order to ensure the continuity of control, it is necessary to maintain an appropriate level of the battery state of charge $(\mathrm{SoC})$. For this purpose, the designed control system measures the value and direction of the current $I$ in the power line. On the basis of the actual voltage level $V_{\mathrm{w}_{-} \mathrm{n}}$, the $S o C$ of the battery, and the anticipated gradient of the power demand (current level of the load daily variation-see Section 3) a decision was made about charging or discharging the ESU. Power line load values are converted to relative units taking into account the assumed daily load profile. The output signals of the energy storage controller are reference active power $P_{\text {ref }}$ and reference reactive power $Q_{\text {ref. }}$ After receiving information about the desired power values $P_{\text {ref }}$ and $Q_{\text {ref }}$, the ESU shall adapt their output power to the $P_{\mathrm{ESU}}$ and $Q_{\mathrm{ESU}}$ accordingly. The model of the controller was developed in the Power Factory flow software, using the internal DPL programming language. 


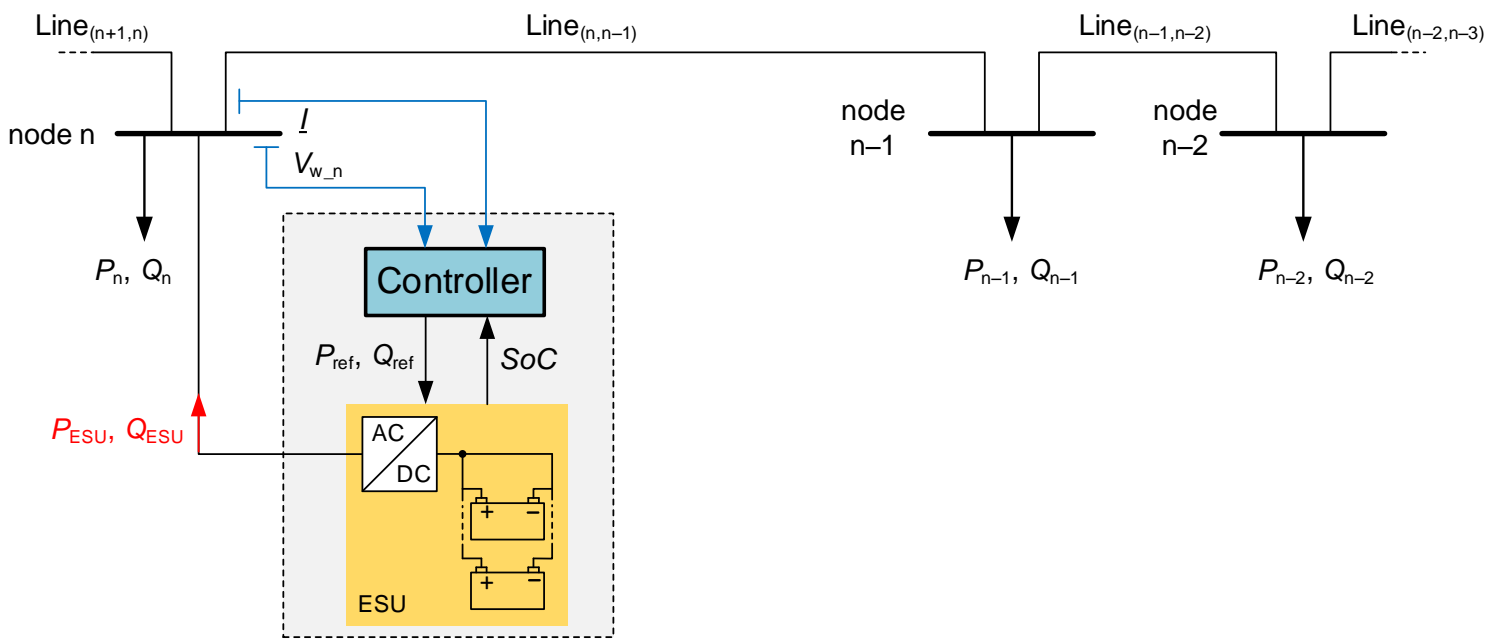

Figure 2. The schematic diagram of the proposed energy storage control system.

A controller based on fuzzy logic is used to control the ESU. A diagram of the fuzzy controller operation is presented in Figure 3. The input data is fuzzified according to the characteristics described in Figure 4. Then the data is subjected to further analysis which is carried out using the Defined Rules Base in the Inference Block. After the inference process, the fuzzy values of $\mu P$ and $\mu Q$ must undergo the defuzzification process. It is the process that maps fuzzy values of $\mu P$ and $\mu Q$ to a crisp set of values of $P_{\text {ref }}$ and $Q_{\text {ref }}$. Only such values of active and reactive power setpoints $P_{\text {ref }}$ and $Q_{\text {ref }}$ can be sent as a set signal to the energy storage unit.

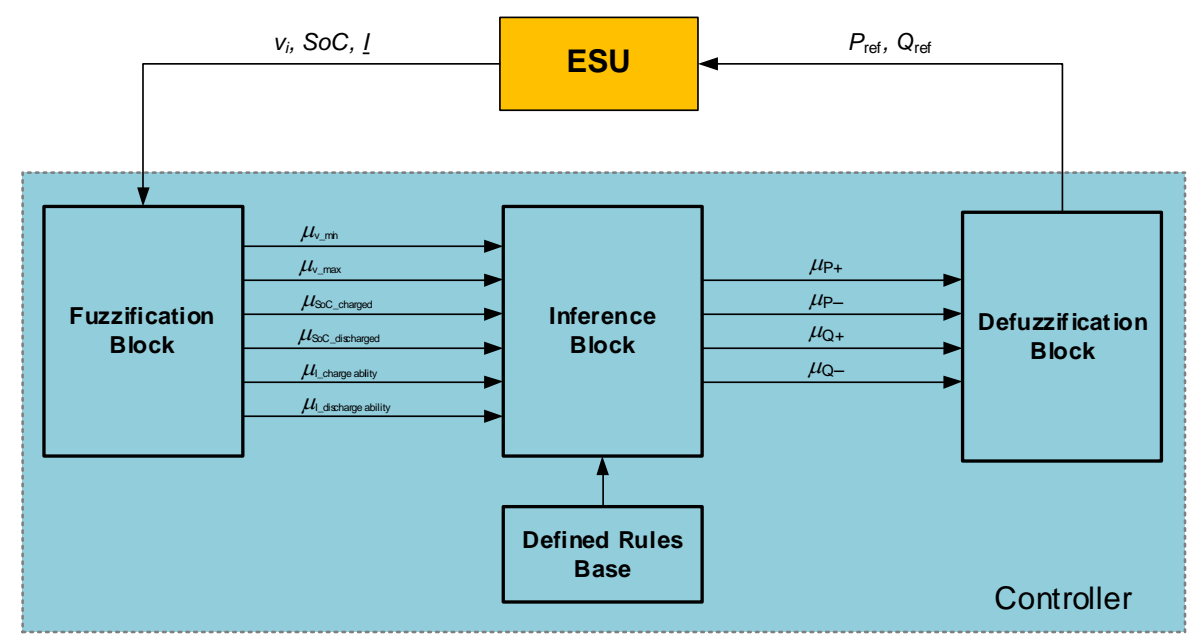

Figure 3. The scheme of a fuzzy controller for the ESU.

The membership functions for individual input variables take the following shapes and values:

- $\quad \mu_{\mathrm{V}}-$ membership function for the voltage $V_{\mathrm{i}}$ in the connection node of the ESU. The membership function for the 'too high' voltage fuzzy values is shown in Figure 4a, whereas the membership function for the fuzzy voltage values 'too low' is shown in Figure $4 \mathrm{~b}$. The values of $V_{\min }, V^{\prime}{ }_{\min }$ ' $V_{\max }^{\prime}$, and $V_{\max }$ may be the same as $V_{\operatorname{minB}}, V_{\min A}, V_{\operatorname{maxA}}$, and $V_{\operatorname{maxB}}$, respectively, included in (7).

- $\mu_{\mathrm{SoC}}$-membership function for the state of charge of a given SoC ESU; it was assumed that the ESU as an electrochemical battery can operate in the range from $20 \%$ to $80 \%$ [57] of its capacity $\left(S o C_{\min }=0.2, S o C_{\max }=0.8\right)$. Membership function for the fuzzy values of the charge state of a specific reservoir as 'charged' is shown in Figure 4c; the membership function for the state loading of a specific 'discharged' reservoir is shown in Figure $4 \mathrm{~d}$. 
- $\quad \mu_{I}$-membership function which defines ability of the power grid/line to charge or discharge the ESU; the ability of the power grid/line to discharge the ESU is with subscript 'discharge ability' (Figure 4e) and the ability of the power grid/line to charge the ESU is with subscript 'charge ability' (Figure 4f). The range of $I_{1}, I_{2}, I_{1}{ }^{\prime}, I_{2}$ ' values is from -1 to 1 , because the value of the current is in a relative unit related to the maximum value of the current. The values of $I_{1}, I_{2}, I_{1}{ }^{\prime}$, $I_{2}{ }^{\prime}$ are determined in the process of parameters optimization on the basis of given load profiles, as described further in the paper.

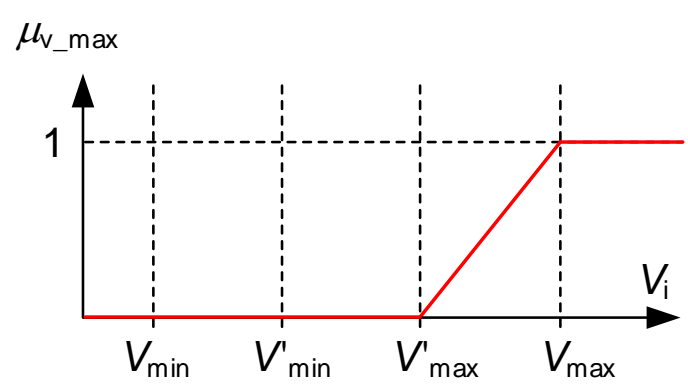

(a)

$\mu_{\text {SoC_charged }}$

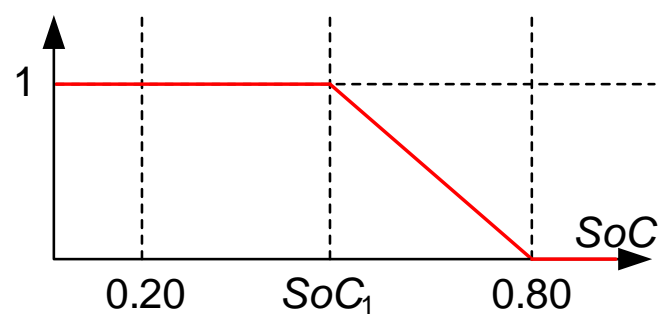

(c)

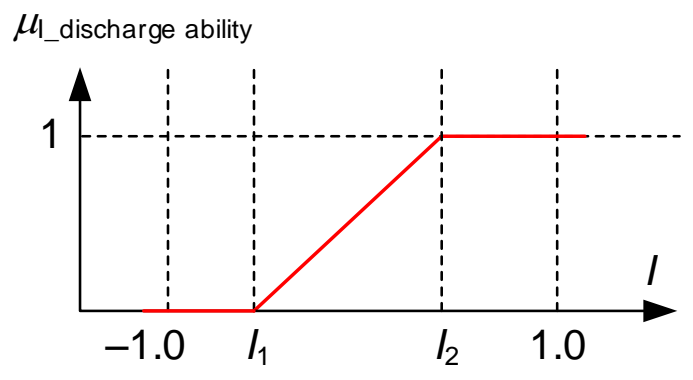

(e)

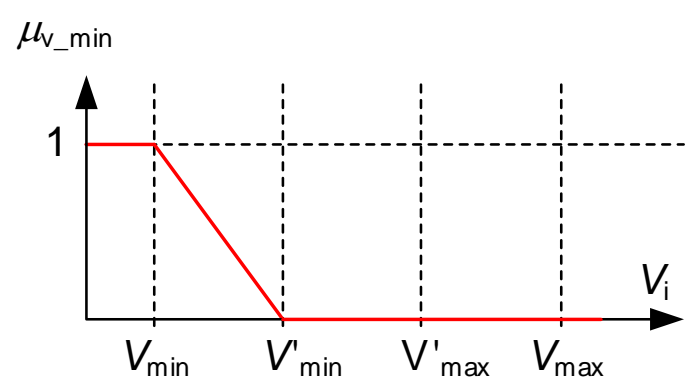

(b)

$\mu_{\text {SoC_discharged }}$

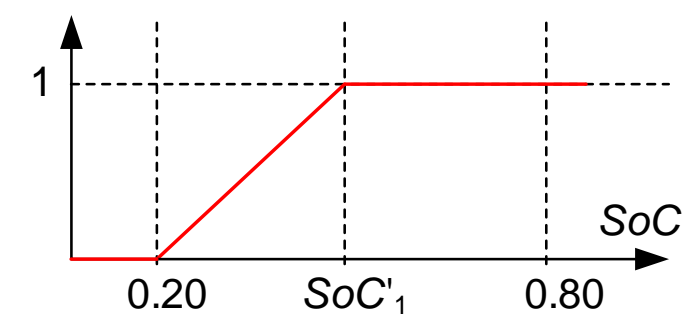

(d)

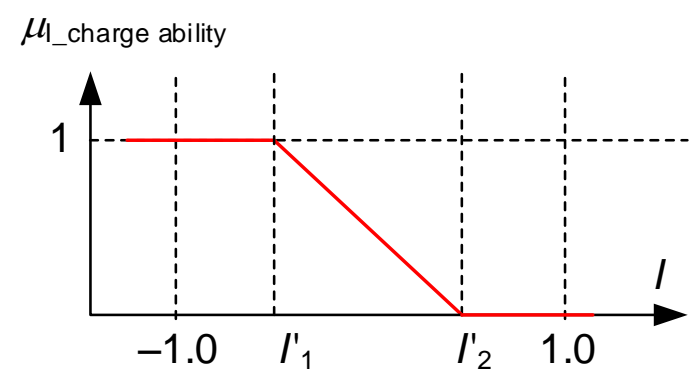

(f)

Figure 4. The membership functions for individual input. (a) Voltage value is determined as 'too low'; (b) voltage value is determined as 'too high'; (c) SoC of the ESU is determined as 'charged'; (d) SoC of the ESU is determined as 'discharged'; (e) power line has 'discharge ability'; (f) power line has 'charge ability'.

Membership functions for reference active power $P_{\text {ref }}$ and reference reactive power $Q_{\text {ref }}$ are depicted in Figure 5. 


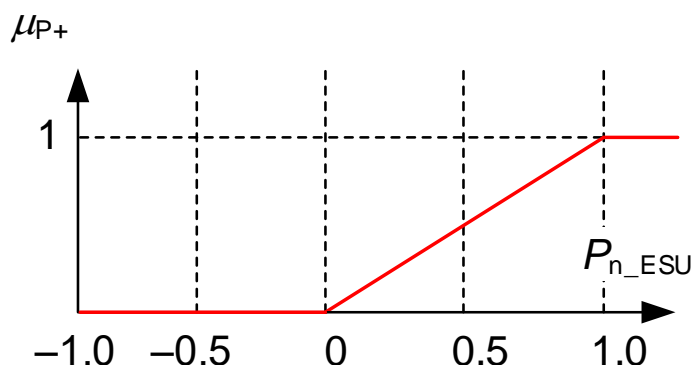

(a)

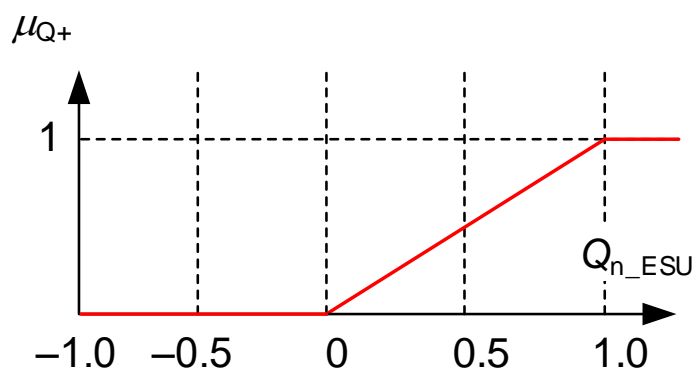

(c)
$\mu_{\mathrm{P}-}$

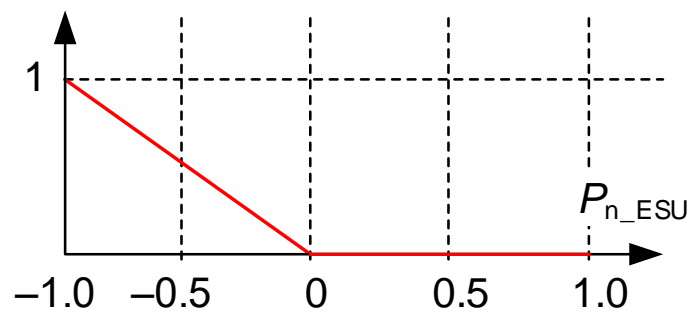

(b)

$\mu_{\mathrm{Q}-}$

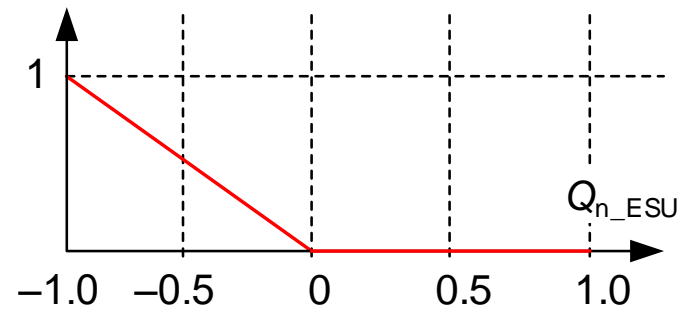

(d)

Figure 5. The membership functions for individual output variables: (a) to deliver active power to the grid; (b) to get active power from the grid; (c) to deliver reactive power to the grid; (d) to get reactive power from the grid.

A decision block consists of a rule base and an inference machine. The rule base describes the relationship between the individual input variables and translates them into appropriate output decision drivers. The rule base for the energy storage controller is as follows:

1. IF the voltage is 'too low' and the ESU is 'charged', THEN 'deliver the active power to the grid'.

2. IF the voltage is 'too low' and the ESU is 'discharged', THEN 'deliver reactive power to the grid'.

3. IF the voltage is 'too high' and the ESU is 'discharged', THEN 'get active power from the grid'.

4. IF the voltage is 'too high' and the ESU is 'charged', THEN 'get reactive power from the grid'.

5. IF the voltage is NOT 'too high' AND the ESU is 'charged' AND the value of the current in the line indicates 'discharge ability', THEN 'deliver active power to the grid'.

6. IF the voltage is NOT 'too low' AND the ESU is 'discharged' AND the value of the current in the line indicates 'charge ability', THEN 'get active power from the grid'.

The inference machine operates on the principle of the Mamdani fuzzy implication for rules $1 \div 4$, which is determined for example in rule 1 by the formula (13). The Mamdani fuzzy implication was chosen because the values of both membership functions $\left(\mu_{\mathrm{V}}\right.$ and $\left.\mu_{\mathrm{SoC}}\right)$ are equally important in the decision of ESU operation (charging/discharging):

$$
\mu_{\mathrm{v}_{\text {min }} \rightarrow \mathrm{SoC}_{\text {charged }}}\left(V_{\mathrm{i}}, \mathrm{SoC}\right)=\min \left[\mu_{\mathrm{v}_{\min }}\left(V_{\mathrm{i}}\right), \mu_{\mathrm{SoC}_{\text {charged }}}(\mathrm{SoC})\right]
$$

Two kinds of implication are used in rules 5 and 6. In the first step, the Mamdani implication is used for membership function of $\mu_{\mathrm{V}}$ and $\mu_{\mathrm{SoC}}$. Then the Larsen implication, described by the formula (14), is used for the result from the first step and for membership function of $\mu_{\mathrm{I}}$ :

$$
\mu_{\mathrm{V}_{\text {min }} \rightarrow \mathrm{SoC}_{\text {charged }}}\left(V_{\mathrm{i}}, \mathrm{SoC}\right)=\mu_{\mathrm{v}_{\text {min }}}\left(V_{\mathrm{i}}\right) \cdot \mu_{\mathrm{SoC}_{\text {charged }}}(\mathrm{SoC})
$$


The first maximum method, counted from the axis $P=0, Q=0$, is used in the defuzzification process. The crisp value of $P_{\text {ref }}$ and $Q_{\text {ref }}$ is the result of achieving the maximum of the membership functions $\mu_{\mathrm{P}}$ and $\mu_{\mathrm{Q}}$, respectively (Figure 6), for the smallest absolute value of $P$ and $Q$.

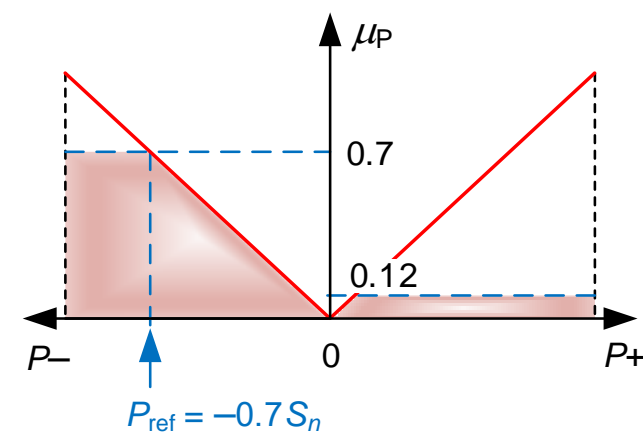

(a)

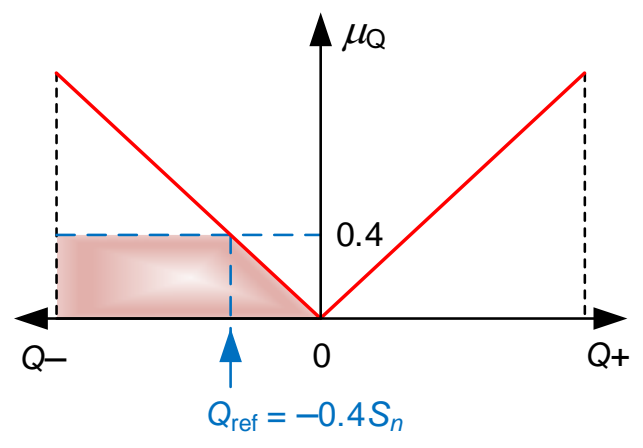

(b)

Figure 6. The function of the defuzzification of (a) active power values; (b) reactive power values; $S_{\mathrm{n}}$ is the rated apparent power of the converter of the ESU.

The controller is parameterized by the appropriate selection of values for the size occurring in the formulas of membership functions (change of parameters of fuzzy numbers) or to change the reference parameters (set of fuzzy numbers). In this case, to specify relevant parameters of membership function, the following cases are considered:

- for the membership functions $\mu_{\text {SoC_charged }}$ and $\mu_{\text {SoC_discharged, }}$ appropriate values of $S o C_{1}$ and $\mathrm{SoC}_{1}{ }^{\prime}$ constants are selected, respectively,

- for the membership functions $\mu_{\mathrm{I} \_\max }$ and $\mu_{\mathrm{I} \_ \text {min }}$, appropriate values of $I_{1}, I_{2}$ and $I_{1}{ }^{\prime}, I_{2}{ }^{\prime}$ constants are selected,

- for the membership functions $\mu_{\mathrm{V}_{-} \min }$ and $\mu_{\mathrm{V}_{-} \max }$, the values are determined as a function of voltage recommended levels for a given grid.

The evolutionary algorithm was used in order to select the appropriate values of the $S_{0} C_{1}$ and So $C_{1}{ }^{\prime}$ constants as well as $I_{1}, I_{2}, I_{1}{ }^{\prime}$, and $I_{2}{ }^{\prime}$. The operation of the evolutionary algorithm that was used for the appropriate selection of parameters of energy storage regulators is based on a similar principle as the operation of the genetic algorithm for selecting the location of ESU in the grid. The difference is in the fact that the previously discussed genetic algorithm operated on integers, and the evolutionary algorithm works with real numbers. The latter algorithm was also created in PowerFactory software. Optimization of the parameters of energy storage controllers is carried out using the daily load variations (similar to the genetic algorithm used for location) and assumes minimizing the voltage deviation in all nodes in the grid during the period under study. The minimization of the voltage deviation $\Delta V_{\mathrm{i}}$ from the permissible values $V_{\min }$ and $V_{\max }$ is a function. The objective function $M$ of the evolutionary algorithm is described by the formulas (15) and (16):

$$
\begin{gathered}
M=\min \left\{\sum_{t=1}^{T}\left(\sum_{i=1}^{N} \Delta V_{\mathrm{i}}\right)\right\} \\
\Delta V_{\mathrm{i}}=\left\{\begin{array}{c}
\Delta V_{\mathrm{i}}=\left(V_{\min }-V_{\mathrm{i}}\right), \text { where }\left(V_{\mathrm{i}}<V_{\min }\right) \\
\Delta V_{\mathrm{i}}=\left(V_{\mathrm{i}}-V_{\max }\right), \text { where }\left(V_{\mathrm{i}}>V_{\max }\right) \\
\Delta V_{\mathrm{i}}=0, \text { where }\left(V_{\mathrm{i}}>V_{\min }\right) \wedge\left(V_{\mathrm{i}}<V_{\max }\right)
\end{array}\right.
\end{gathered}
$$

where:

$V_{\mathrm{i}}$-voltage value in node $i$, 
$V_{\max }$ - the maximum permissible voltage in the grid,

$V_{\min }$-minimum permissible voltage in the grid,

$\Delta V_{\mathrm{i}}$-voltage deviation from the permissible value in node $i$,

$T$-number of time steps $(T=96)$,

$M$-value of the objective function to optimize the selection of parameters for the energy storage controller,

$N$-number of nodes in the grid.

The flow chart of the algorithm related to the selection of the location and parameters of the ESU and their controller parameters for individual ESU is shown in Figure 7 and is called an integrated algorithm. In the integrated algorithm the selection of optimal controller parameters is part of the optimization of the location selection of ESU. The configuration of ESU in the grid is assigned to the parameter values of ESU controllers determined for the objective function $M$ that has reached the minimum value of $M_{\mathrm{min}}$. The result of the integrated optimization is the choice of the configuration of ESU in the power grid for which the value of the objective function $f$ will reach the highest value $f_{\max }$.

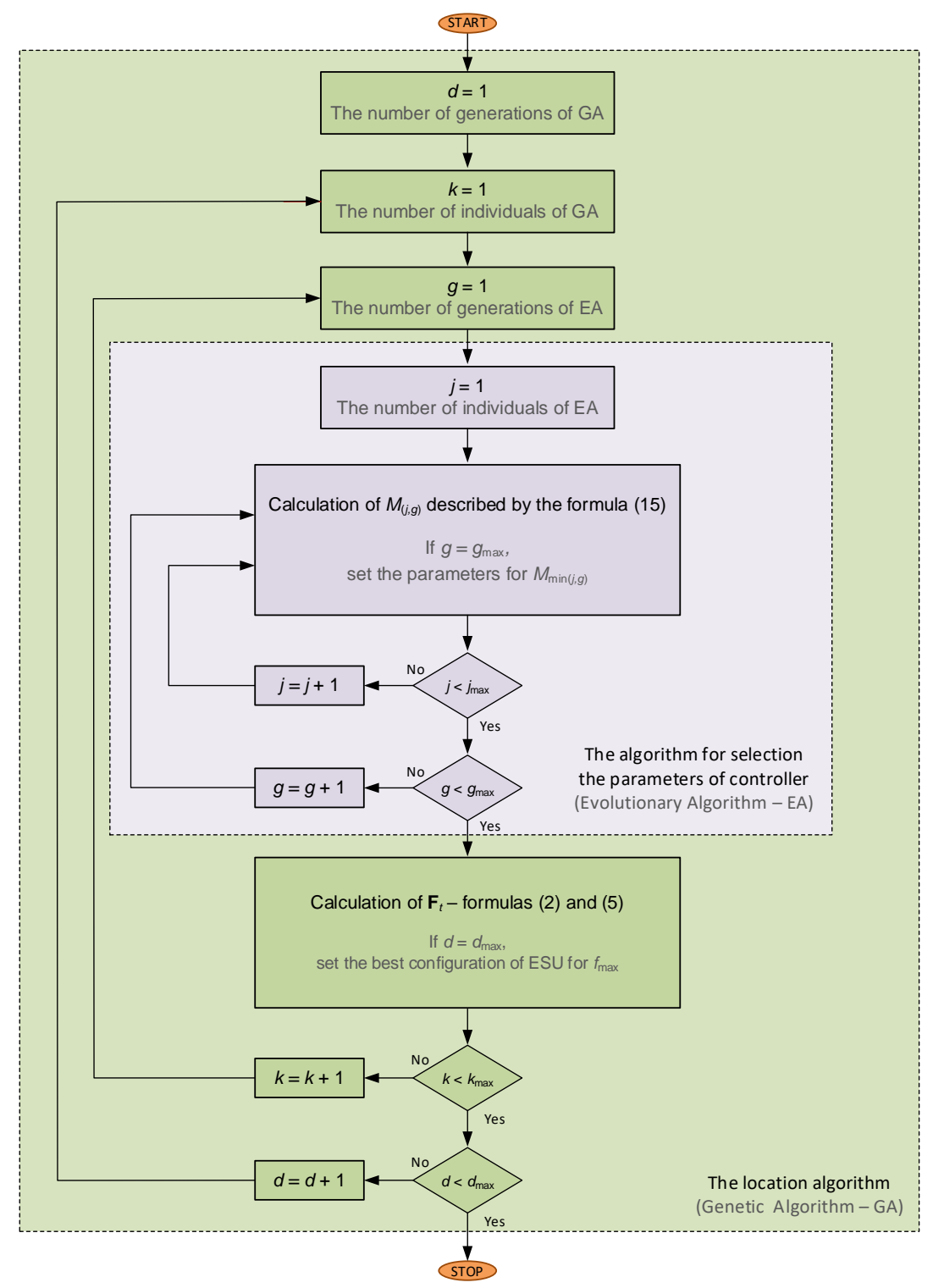

Figure 7. An integrated algorithm for selection of the location and control of ESU (for symbols see Appendix A). 


\section{Results}

\subsection{Description of Analyzed Example Grid for the Integrated Algorithm Validation}

A real LV grid area consisting of 19 nodes was selected for the analysis. The structure of the grid is presented in Figure 8 . The power generation in nodes within the range $(3 \div 40) \mathrm{kW}$ was modeled. The analyzed grid contains RES (PV sources) which make a relatively high variation of the voltage level. The sources are located at end of the circuit, at six consumers (Lo 521, Lo 524, Lo 525, Lo 527, Lo 528, Lo 530). Two exemplary load profiles (A and B) were assumed in the analysis. Daily variations of power in particular nodes, for the aforementioned profiles, are presented in Figure 9.

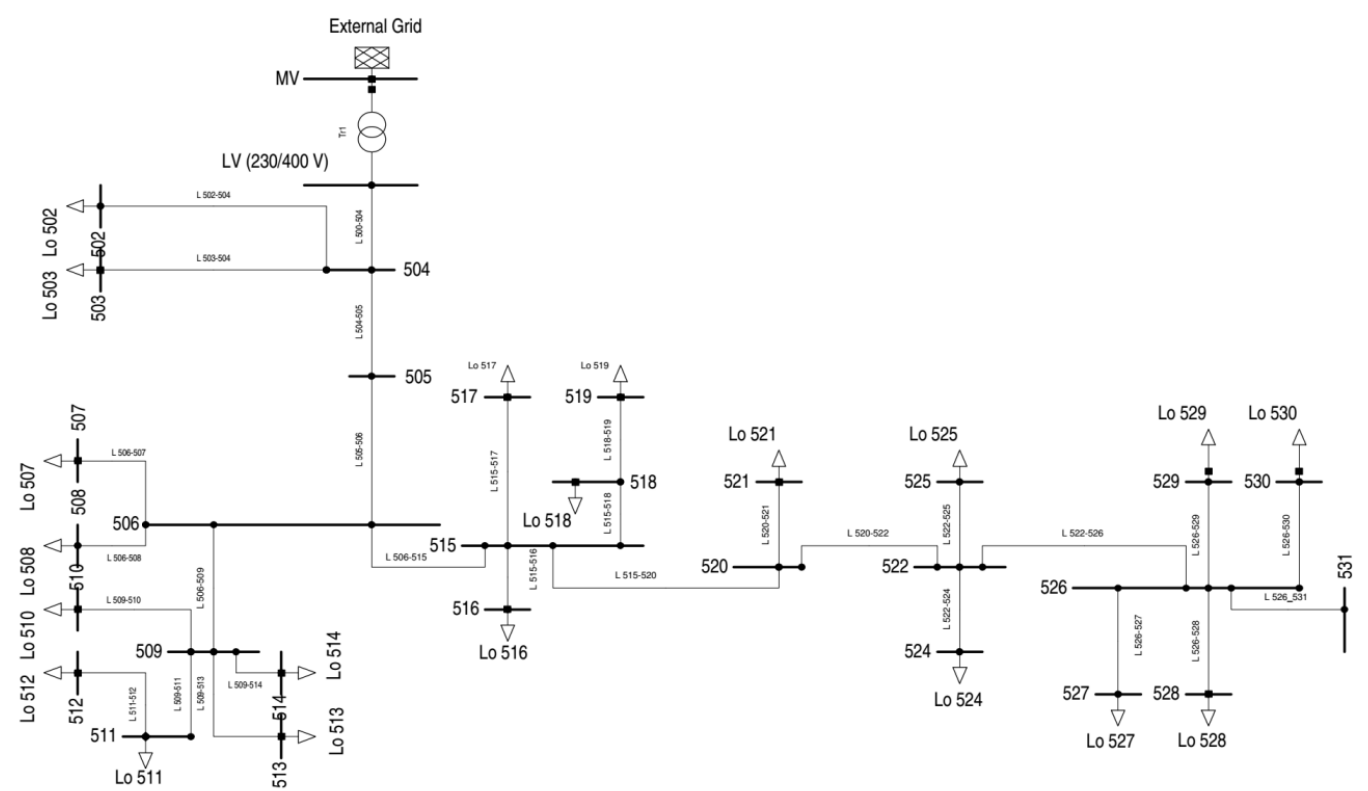

Figure 8. The scheme of the analyzed LV grid; nodes markings 502 .. 531, line markings: e.g., Lo 504-505, the load marking: e.g., Lo 502.

In order to stabilize the voltage level in the grid, it was proposed to use ESU currently available on the market (Table 1). Using the developed localization algorithm, the analysis included all components of the objective function $f$ described by the formula (5). It was assumed that the installation of ESU is possible in each node of the power grid.

The first component of the objective function of the location selection algorithm and parameters selection was based on minimizing the costs associated with failure to maintain an appropriate voltage level in the grid. The values of $V_{\min A}$ and $V_{\min B}$ were determined in accordance with the requirements specified in [54] and adopted as follows: $V_{\min }=0.9 V_{\text {ref }}$ ( $V_{\text {ref }}$ reference value of voltage), $V_{\operatorname{minB}}=0.8 V_{\text {ref. }}$. The value of $V_{\operatorname{minB}}=0.8 V_{\text {ref }}$ determines the lower limit at which there is still the possibility of using electric power by consumers. According to [54], the upper values of $V_{\operatorname{maxA}}$ and $V_{\text {maxB }}$ should be, respectively: $V_{\text {maxA }}=1.1 V_{\text {ref }}, V_{\operatorname{maxB}}=1.2 V_{\text {ref }}$. However, due to the existence of RES, the values of $V_{\operatorname{maxA}}$ and $V_{\operatorname{maxB}}$ were assumed in the simulation on a level narrower than indicated in [54] and they are, respectively: $V_{\operatorname{maxA}}=1.08 V_{\text {ref }}, V_{\operatorname{maxB}}=1.1 V_{\text {ref. }}$ The purpose of setting such values is to provide prosumers with the ability to inject power into grids from renewable sources. In case of reaching the value of voltage equal to $1.1 V_{\text {ref }}$ in the node, the automatic disconnection of the PV installation from the power grid occurs and disables the injection of power to the grid. From the prosumer point of view (in terms of the possibility to inject to the grid the power from PV sources), the voltage in the grid equal to $1.1 V_{\text {ref }}$ has the same unfavorable feature as $1.2 V_{\text {ref }}$. 


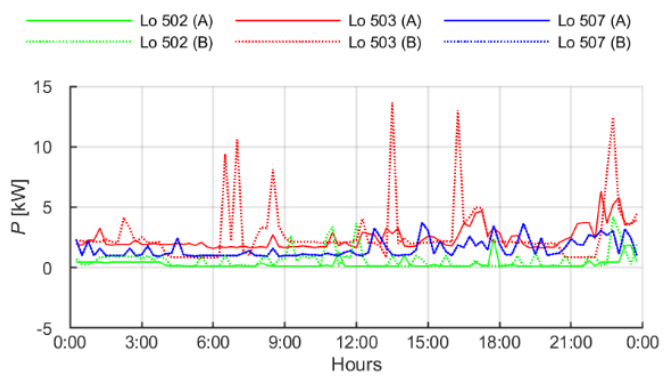

(a)

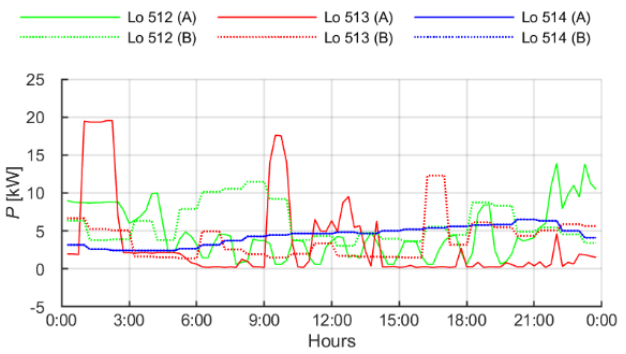

(c)

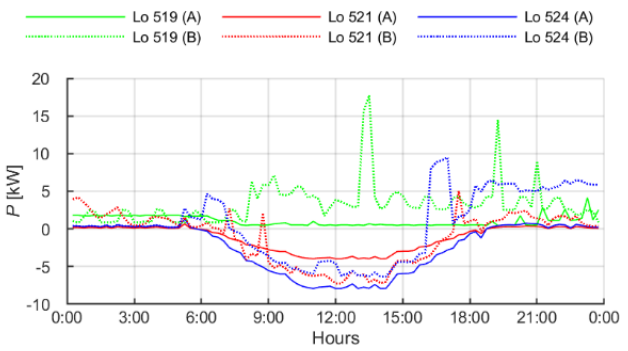

(e)

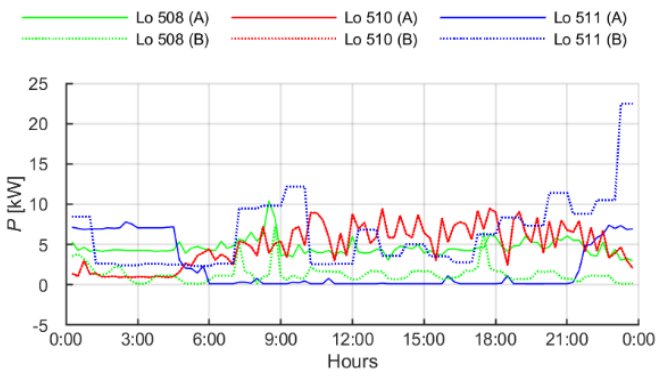

(b)

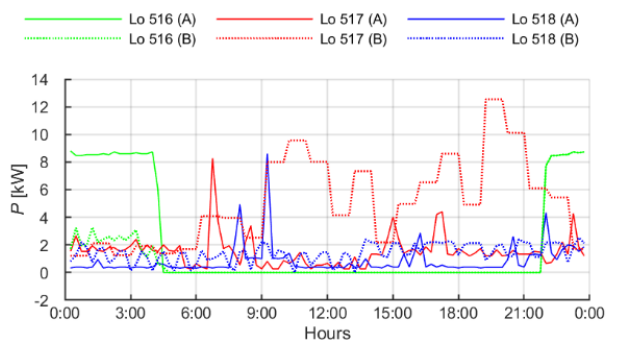

(d)

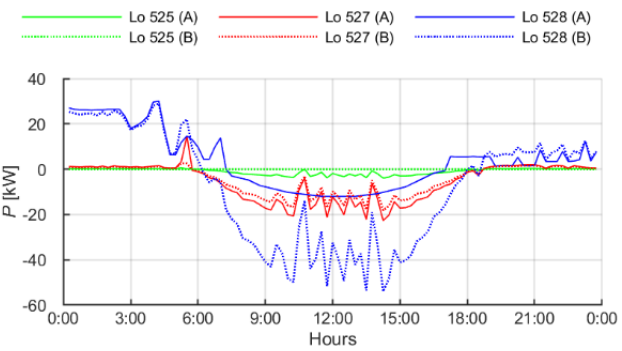

(f)

Figure 9. Daily variations of the power in the analyzed LV grid (without ESU); (a) nodes 502, 503, 507, (b) nodes 508, 510, 511, (c) nodes 512, 513, 514, (d) nodes 516, 517, 518, (e) nodes 519, 521, 524, (f) nodes 525, 527, 528; (A)—profile A, (B)—profile B.

\subsection{Simulation Results}

The results of the simulations (selecting the location and parameters of energy storage controllers) for two assumed load profiles are included in the following tables and figures:

- $\quad$ profile A-Tables 2 and 3 as well as Figures 10-15,

- $\quad$ profile B-Tables 4 and 5 as well as Figures 16-21.

Table 2. The result of selecting the location and parameters of ESU for the analyzed LV grid (load profile A).

\begin{tabular}{cccccc}
\hline Node No. & $\mathbf{5 2 2}$ & $\mathbf{5 2 6}$ & $\mathbf{5 2 8}$ & $\mathbf{5 2 9}$ & $\mathbf{5 3 0}$ \\
\hline Power $(\mathrm{kW})$ & 4.8 & 4.8 & 8.2 & 6.4 & 6.4 \\
Capacity $(\mathrm{kWh})$ & 9.0 & 9.0 & 13.5 & 12.0 & 12.0 \\
\hline
\end{tabular}


Table 3. Controller parameters for the individual ESU (load profile A).

\begin{tabular}{cccccc}
\hline Node No. & $\mathbf{5 2 2}$ & $\mathbf{5 2 6}$ & $\mathbf{5 2 8}$ & $\mathbf{5 2 9}$ & $\mathbf{5 3 0}$ \\
\hline$S o C_{1}$ & 0.641 & 0.685 & 0.614 & 0.577 & 0.522 \\
$S o C_{1^{\prime}}$ & 0.683 & 0.700 & 0.663 & 0.682 & 0.651 \\
$I_{1}$ & 0.716 & -0.853 & -0.308 & -0.685 & -0.392 \\
$I_{2}$ & 0.856 & -0.808 & -0.299 & -0.169 & 0.105 \\
$I_{1^{\prime}}$ & 0.899 & 0.452 & 0.667 & 0.054 & 0.441 \\
$I_{2^{\prime}}$ & 0.890 & 0.474 & 0.745 & 0.406 & 0.560 \\
\hline
\end{tabular}

Table 4. The result of selecting the location and parameters of ESU for the analyzed LV grid (load profile B).

\begin{tabular}{ccccccccc}
\hline Node No. & $\mathbf{5 2 0}$ & $\mathbf{5 2 1}$ & $\mathbf{5 2 4}$ & $\mathbf{5 2 5}$ & $\mathbf{5 2 6}$ & $\mathbf{5 2 7}$ & $\mathbf{5 2 8}$ & $\mathbf{5 2 9}$ \\
\hline Power $(\mathrm{kW})$ & 9.0 & 9.0 & 9.0 & 9.0 & 9.0 & 9.0 & 9.0 & 8.2 \\
Capacity $(\mathrm{kWh})$ & 14.0 & 14.0 & 14.0 & 14.0 & 14.0 & 14.0 & 14.0 & 13.5 \\
\hline
\end{tabular}

Table 5. Controllers parameters for individual ESU (load profile B).

\begin{tabular}{ccccccccc}
\hline Node No. & $\mathbf{5 2 0}$ & $\mathbf{5 2 1}$ & $\mathbf{5 2 4}$ & $\mathbf{5 2 5}$ & $\mathbf{5 2 6}$ & $\mathbf{5 2 7}$ & $\mathbf{5 2 8}$ & $\mathbf{5 2 9}$ \\
\hline SoC $_{1}$ & 0.511 & 0.592 & 0.468 & 0.300 & 0.491 & 0.300 & 0.606 & 0.300 \\
So $_{1^{\prime}}$ & 0.524 & 0.600 & 0.646 & 0.628 & 0.491 & 0.462 & 0.700 & 0.300 \\
$I_{1}$ & 0.288 & -0.863 & 0.097 & -0.034 & 0.069 & 0.758 & 0.154 & -0.052 \\
$I_{2}$ & 0.334 & 0.393 & 0.521 & 0.003 & 0.118 & 0.896 & 0.672 & -0.018 \\
$I_{1^{\prime}}$ & 0.711 & 0.812 & 0.527 & 0.013 & 0.142 & 0.924 & 0.743 & 0.007 \\
$I_{2^{\prime}}$ & 0.740 & 0.915 & 0.531 & 0.044 & 0.148 & 0.924 & 0.758 & 0.319 \\
\hline
\end{tabular}

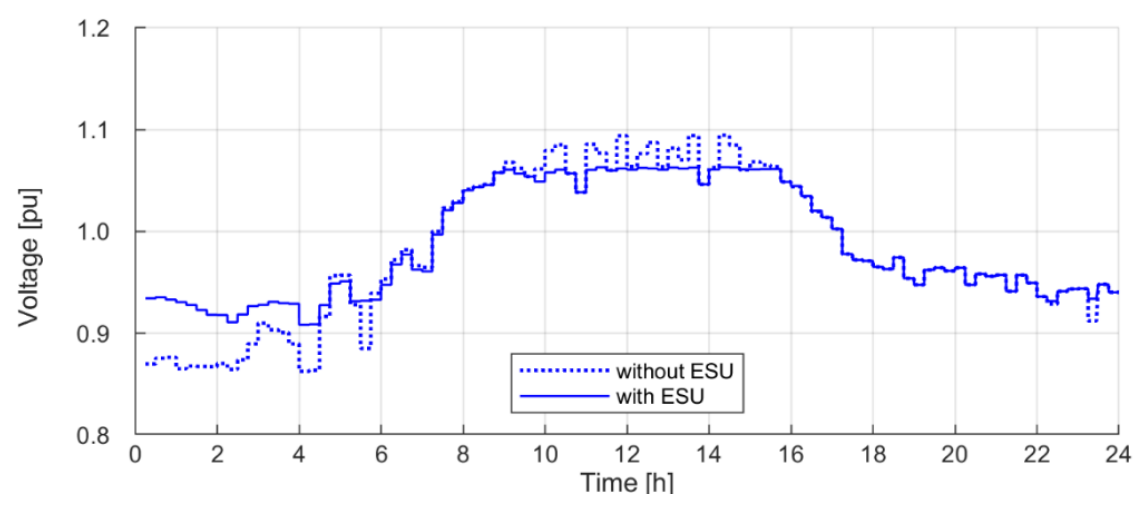

Figure 10. Daily voltage variations in node 522 (profile A).

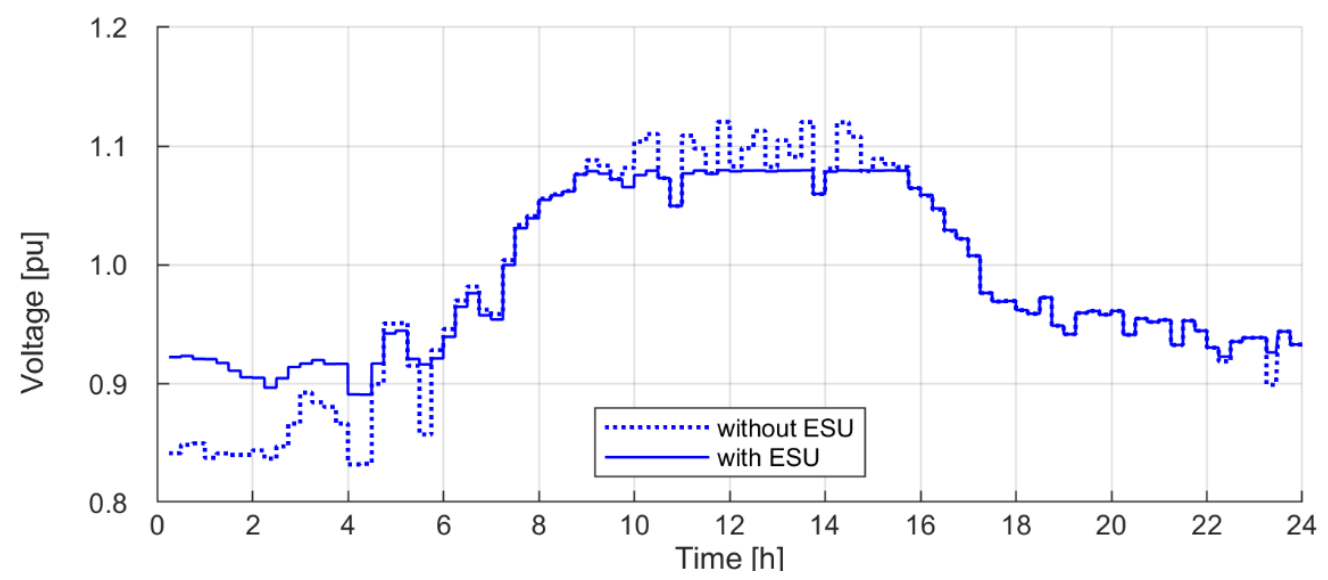

Figure 11. Daily voltage variations in node 526 (profile A). 


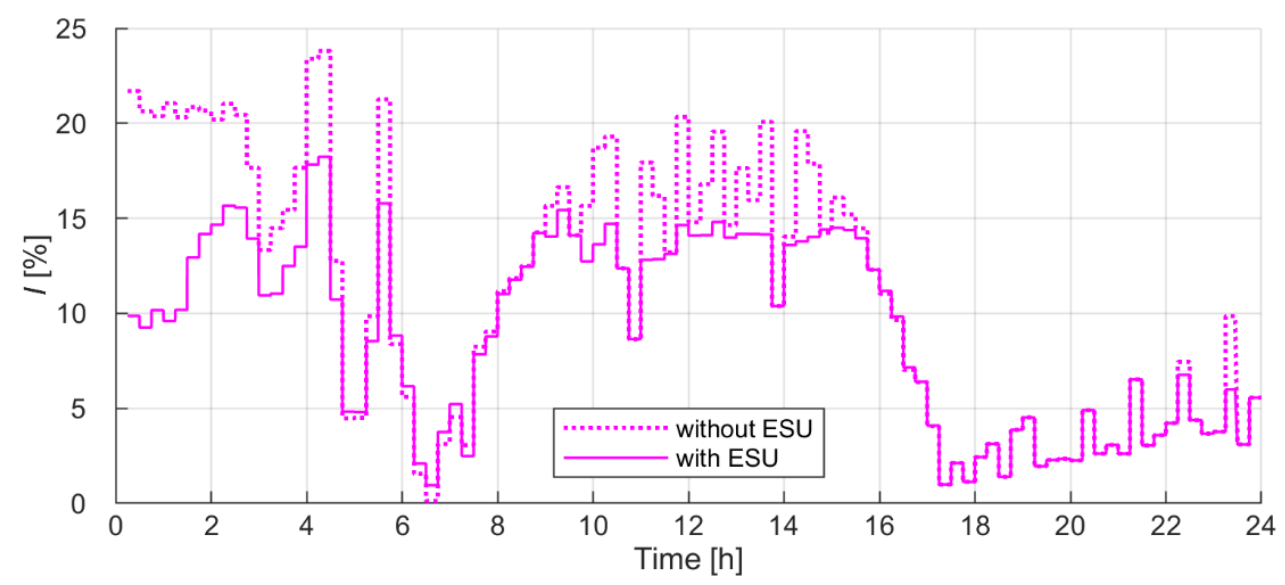

Figure 12. Daily load current variations in line L 522-526 (profile A).

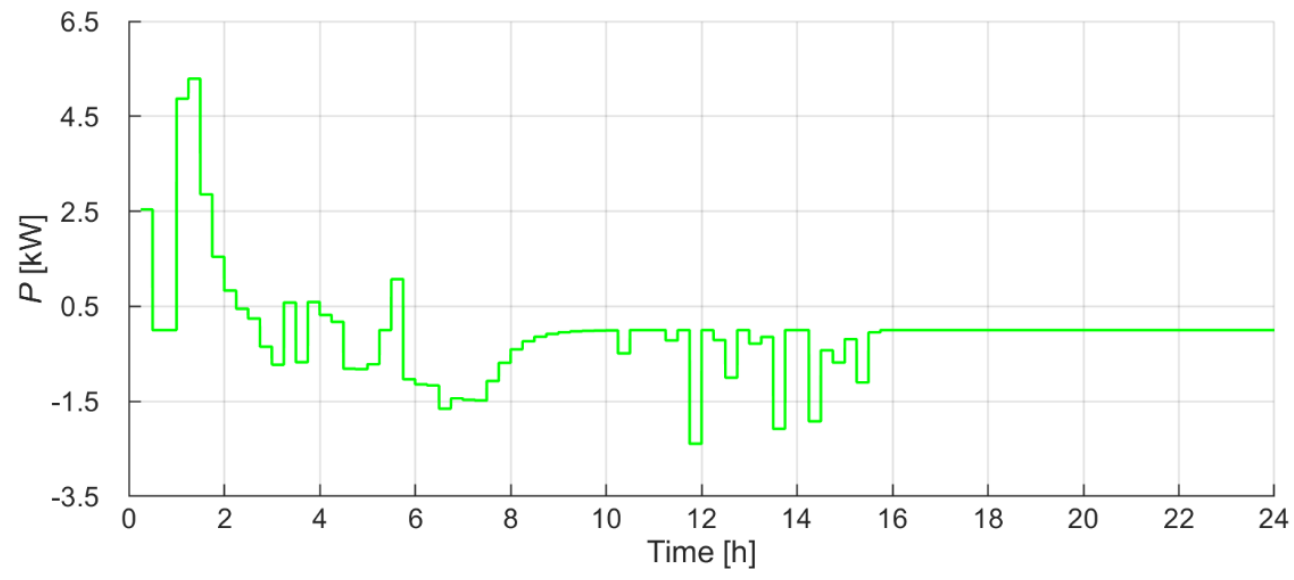

Figure 13. Daily active power variation of the energy storage unit ES_530 (installed in node 530); profile A.

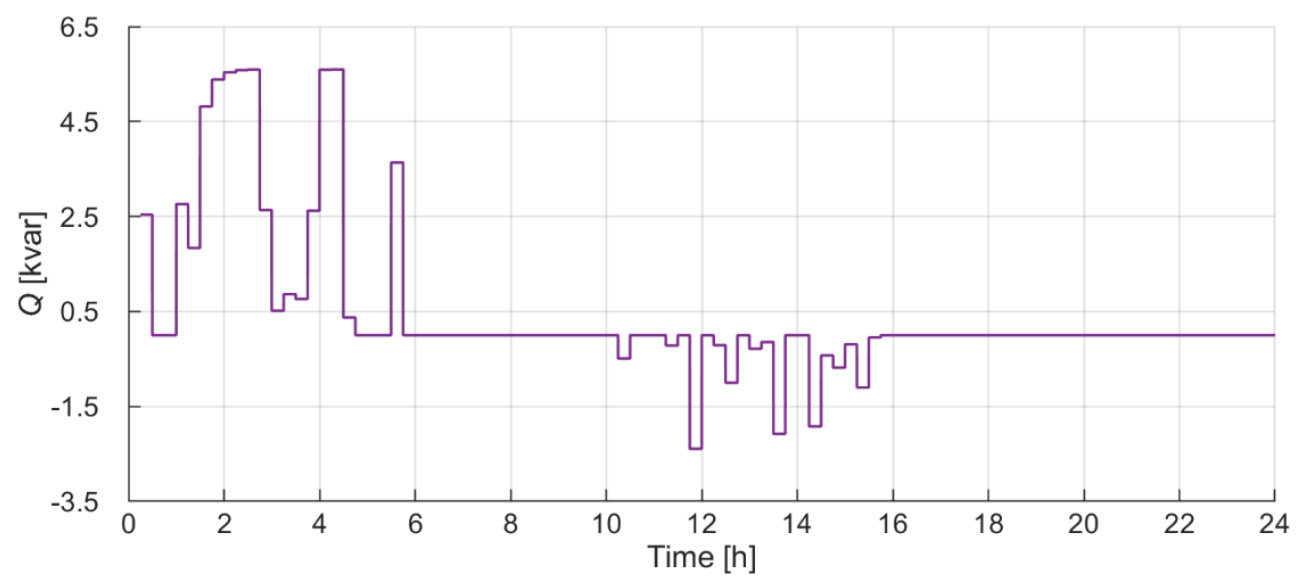

Figure 14. Daily reactive power variation of the energy storage unit ES_530 (installed in node 530); profile A. 


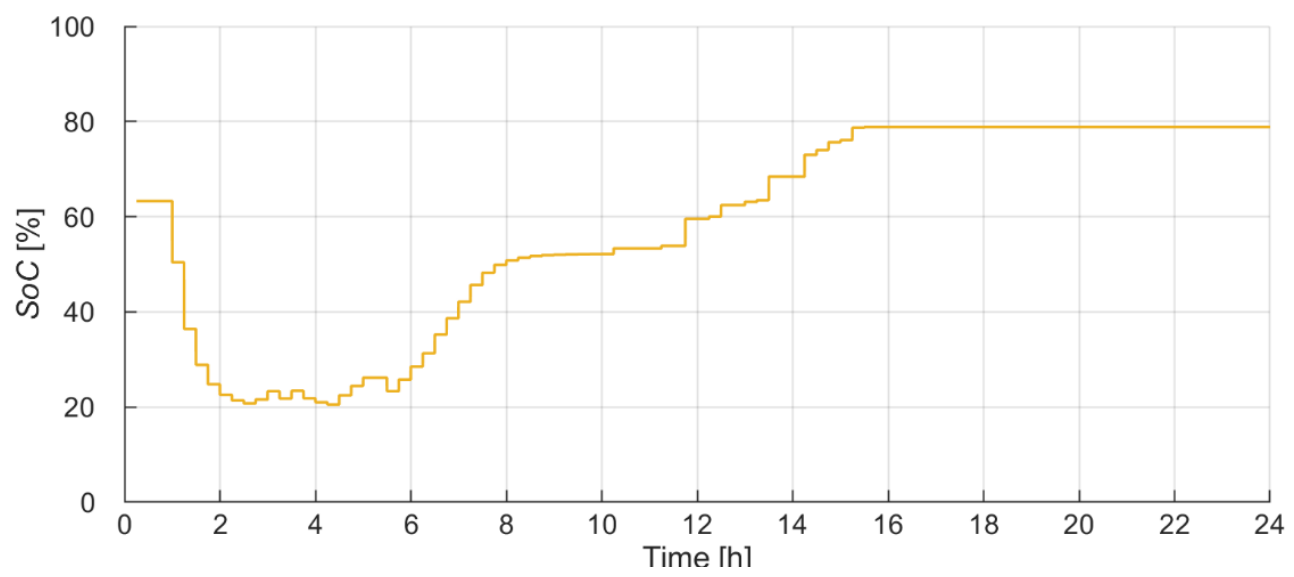

Figure 15. Daily state of charge of the energy storage unit ES_530 (installed in node 530); profile A.

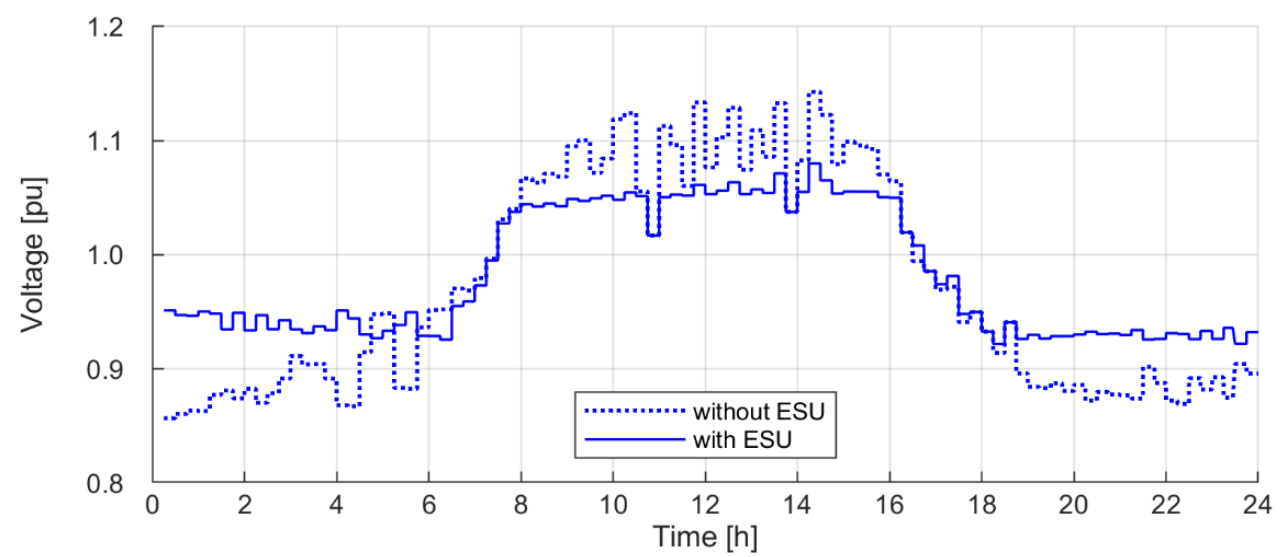

Figure 16. Daily voltage variations in node 522 (profile B).

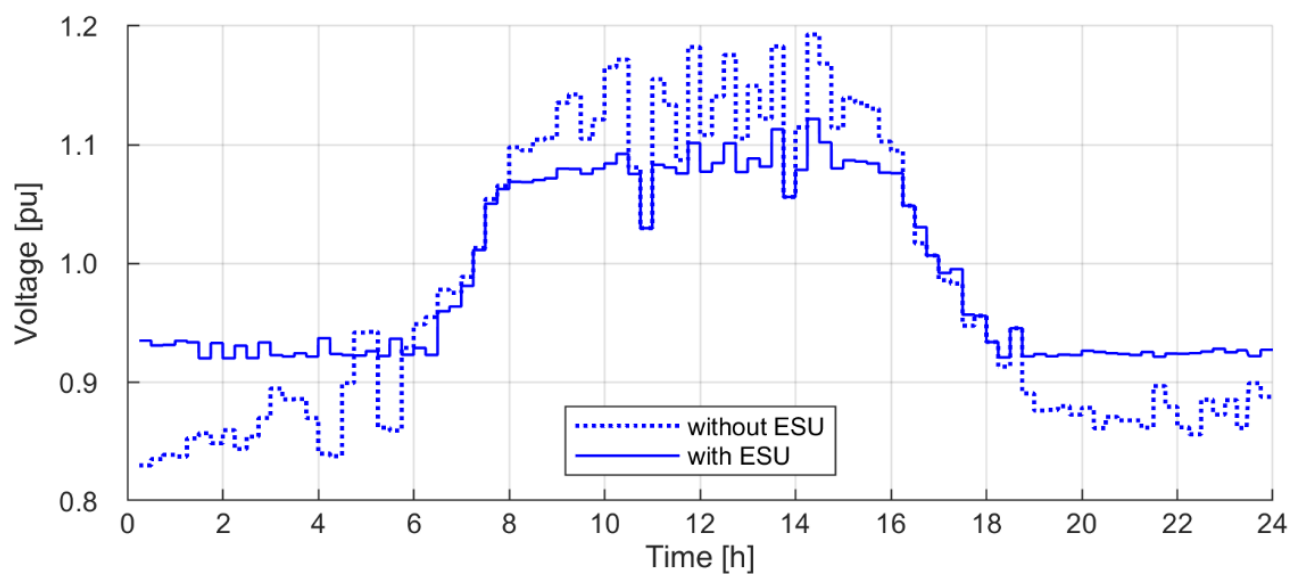

Figure 17. Daily voltage variations in node 526 (profile B). 


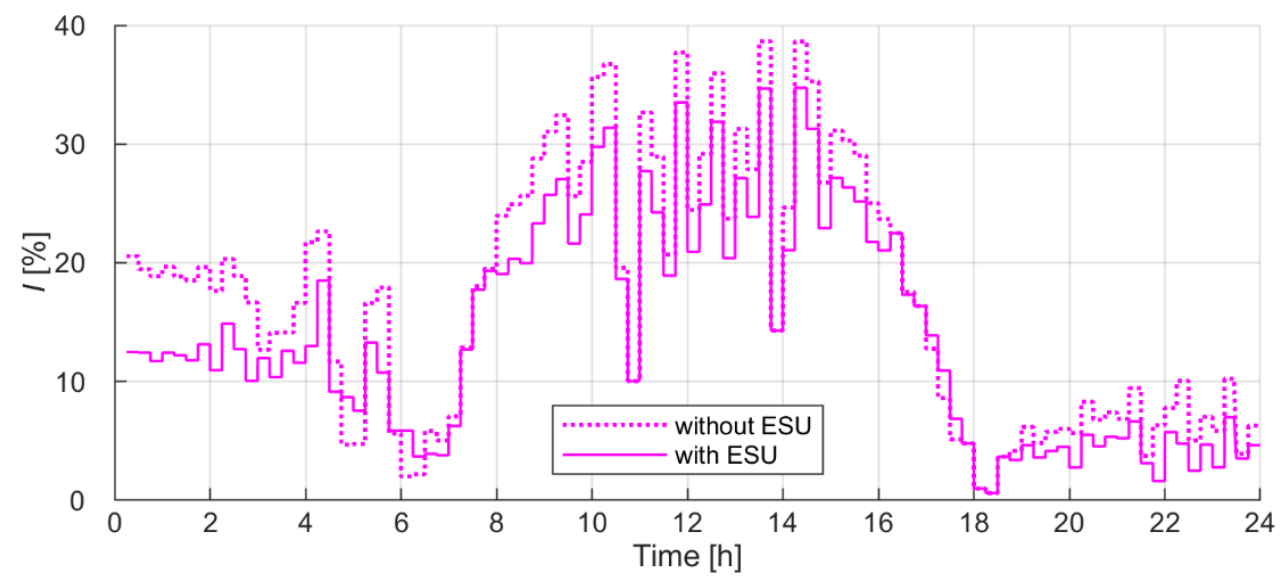

Figure 18. Daily load current variations in line L 522-526 (profile B).

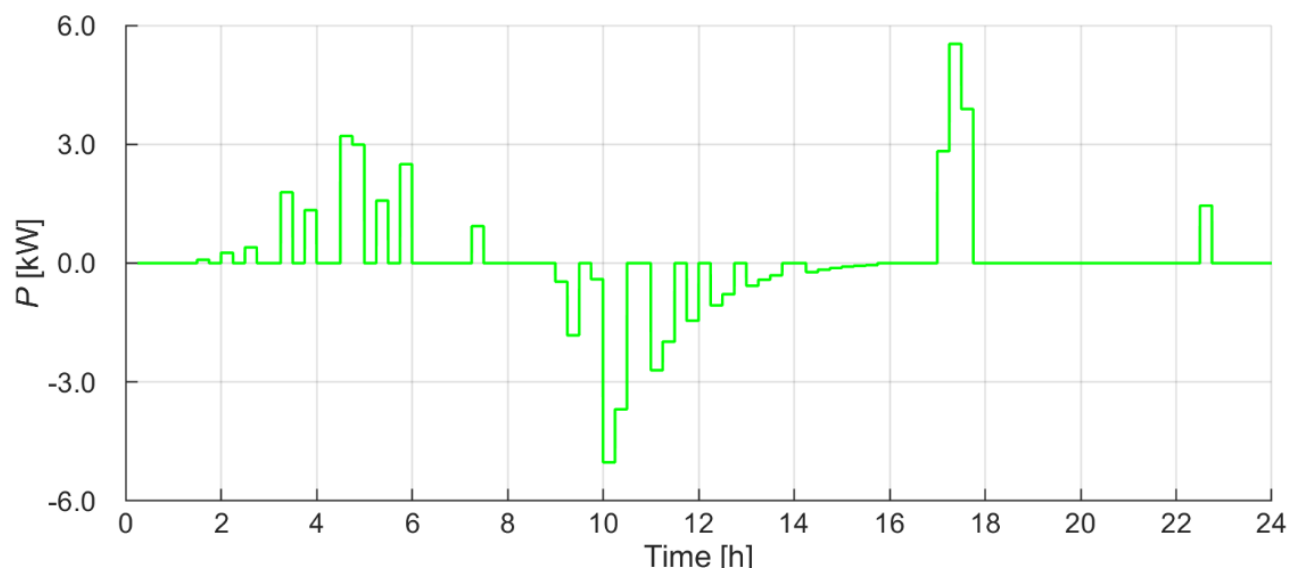

Figure 19. Daily active power variation of the energy storage unit ES_529 (installed in node 529); profile B.

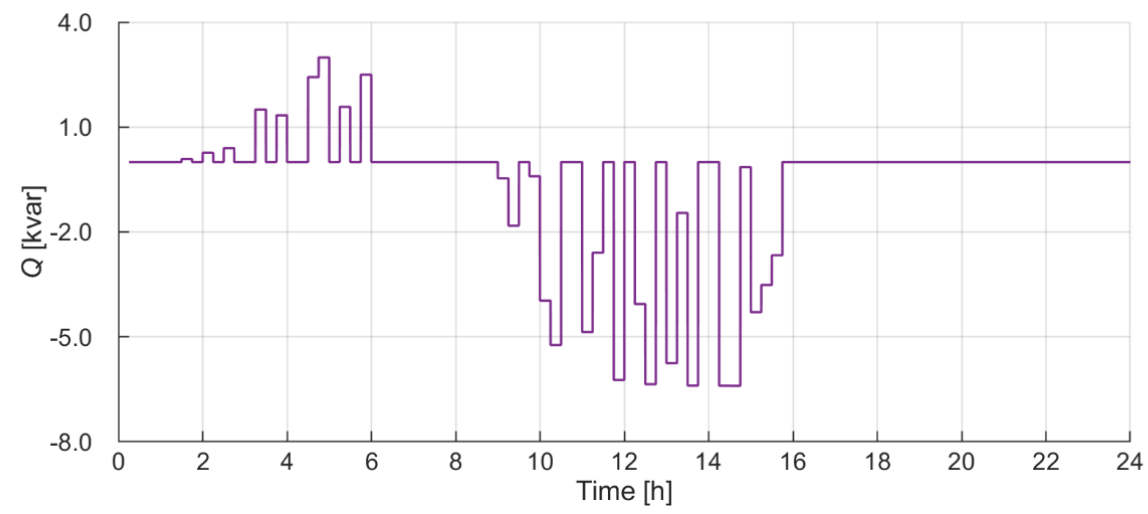

Figure 20. Daily reactive power variation of the energy storage unit ES_529 (installed in node 529); profile B. 


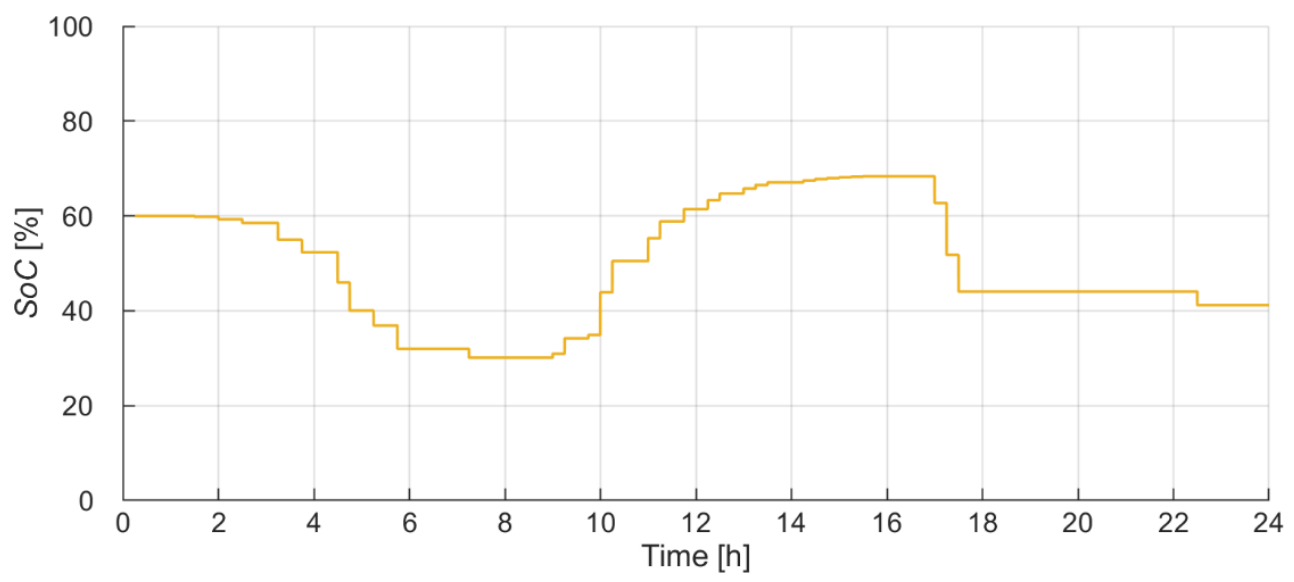

Figure 21. Daily state of charge of the energy storage unit ES_529 (installed in node 529); profile B.

Daily variations of voltage levels for specific nodes (mainly for those nodes where voltage problems have been observed) are presented in Figures 10 and 11 as well as Figures 16 and 17. In Figures 13-15 and Figures 19-21 the power variations of selected ESU are shown: active and reactive as well as the current state of charge of the ESU. The assumed loads in the example power line (L 522-526) are presented in Figure 12 (for profile A) and Figure 18 (for profile B).

In the process of selecting the location, ESU were assigned to the nodes where there are voltage problems related to power generation as well as power consumption. Their configuration allows to optimize the costs related to the installation of devices in the grid, as well at the same time, it ensures an acceptable voltage level at nodes in the analyzed grid. By selecting the appropriate parameters of the controller for each ESU, the effect of 'cooperation' of the installed devices can be achieved. Not all devices deliver and receive active power at the same time, and their operation is optimized to get as much efficiency as possible. Additionally, it is possible to supply reactive power to the grid by ESU, therefore, it maximizes their utilization.

Table 6 presents the share of individual factors in the total costs that are subject to optimization. The results of the calculations are presented for three variants. Variant 1: without ESU in the grid, variant 2: location and parameterization were carried out on the basis of load profile A, variant 3: location and parameterization were carried out on the basis of load profile B.

Application of ESU in the analyzed grid results in the improved voltage profiles. As it is seen in Figures 10, 11, 16 and 17, voltage variations are significantly limited after ESU application. In the grid with ESU, the voltage is significantly closer to the reference value $V_{\text {ref }}$, what gives comfortable conditions for the operation of the current-using equipment of the consumers as well as enables to inject the power from PV sources.

From the analysis of the results presented in Table 6, it can be concluded that in profiles A and B the main factor (for the assumptions made in the simulation) generating the most costs is the failure to meet required voltage value. Improving the voltage level and, thus, reducing costs can be obtained by installing ESU in the power grid. It is worth paying attention to the fact that the higher the costs associated with failure to meet the required voltage level, the more profitable installing ESU in the grid is.

During the consideration of the location of ESU in power grids, particular attention should be paid to the load profile. For the analyzed load profiles A and B, it turns out that the optimal locations of ESU (Table 2 vs. Table 4) in the grid are different and the parameters of the energy storage controllers are also different (Table 3 vs. Table 5). 
Table 6. Daily cost of grid operation: 'without ESU' and 'with ESU' for profiles A and B.

\begin{tabular}{|c|c|c|c|c|c|c|c|}
\hline & Profile Type & & Profile A & & & Profile B & \\
\hline $\begin{array}{l}\text { The Objective } \\
\text { Function } \\
\text { Components }\end{array}$ & Costs & Without ESU & $\begin{array}{c}\text { With ESU } \\
\text { (Optimization to } \\
\text { Profile A) }\end{array}$ & $\begin{array}{c}\text { With ESU } \\
\text { (Optimization to } \\
\text { Profile B) }\end{array}$ & Without ESU & $\begin{array}{c}\text { With ES } \\
\text { (Optimization to } \\
\text { Profile A) }\end{array}$ & $\begin{array}{c}\text { With ESU } \\
\text { (Optimization to } \\
\text { Profile B) }\end{array}$ \\
\hline$p_{1}$ & $\begin{array}{l}\text { The cost related to } \\
\text { appropriate voltage in } \\
\text { grid }(€)\end{array}$ & 26.64 & 0.07 & 0 & 67.52 & 37.86 & 4.76 \\
\hline$p_{2}$ & $\begin{array}{l}\text { The cost of ESU for } \\
t_{\mathrm{p}}=10 \text { (years) } \cdot 365 \\
\text { days }=3650(€ / \text { day })\end{array}$ & 0 & 13.78 & 26.97 & 0 & 13.78 & 26.97 \\
\hline$p_{3}$ & $\begin{array}{l}\text { The cost related to } \\
\text { power losses in the } \\
\text { grid }(€)\end{array}$ & 8.21 & 7.42 & 3.71 & 9.61 & 8.18 & 7.99 \\
\hline$p_{4}$ & $\begin{array}{l}\text { The cost related to } \\
\text { overload of elements } \\
\text { transmission }(€)\end{array}$ & 0 & 0 & 0 & 0 & 0 & 0 \\
\hline & Sum $(€)$ & 34.85 & 21.27 & 30.68 & 77.13 & 59.82 & 39.72 \\
\hline & Savings (€/day) & & 13.58 & 4.17 & & 17.31 & 37.41 \\
\hline
\end{tabular}


Changing the parameters of controllers depending on the adopted one load profile is not expensive. Therefore, the parameters of the controllers should be appropriately adjusted each time, depending on the expected load profile. This will allow for more efficient use of ESU. In turn, when choosing a location of ESU, several load profiles should be analyzed. For example, when choosing a location for ESU cooperating with PV sources, at least the profile with PV generation for a common working day should be taken into account and a load profile on sunny weekend days.

Comparison of the results from Table 6 enables to say that if in a given node profile A exists, the savings are higher for ESU optimization on the basis of profile A: $€ 13.58$ ( $€ 34.85-€ 21.27$ ) than on the basis of profile $B: € 4.17$ ( $€ 34.85-€ 30.68$ ). The same conclusion is valid if in a node profile $B$ exists—saving is $€ 37.41$ ( $€ 77.13-€ 39.72$ ) for the optimization according to profile $B$, and saving is $€ 17.31$ ( $€ 77.13-€ 59.82$ ) for the optimization according to profile $A$. The question of which location of ESU should be used depends on the repeatability of the occurrence of a given load profile:

- If, for example, profile A would occur six times a week, and profile B once a week, then the weekly use of the solution for profile A saves $€ 98.79(6 \times € 13.58+1 \times € 17.31)$ per week, but savings for assumed profile B would amount to $€ 62.43(6 \times € 4.17+1 \times € 37.41)$.

- If profile A would occur five times a week, and profile B twice a week, then per week, using the solution for profile $A$, it is possible to save $€ 102.52$ ( $5 \times € 13.58+2 \times € 17.31)$, but savings for assumed profile B would be $€ 95.67$ ( $5 \times € 4.17+2 \times € 37.41)$.

- If profile A would occur four times a week, and profile B three times a week, then per week, using the solution for profile $A$, it is possible to save $€ 106.25(4 \times € 13.58+3 \times € 17.31)$, but savings for assumed profile B would be $€ 128.91$ ( $4 \times € 4.17+3 \times € 37.41)$.

- If profile A would occur less than four times a week, it is more advantageous to use the solution for locations from profile B.

\section{Conclusions}

This study shows that the use of ESU improves power quality as well as the flexibility of the distribution grid operation. It has also been shown that the location of ESU and the parameters of the ESU controllers affect the cost of ESU application and utilization. In order to select the parameters of ESU and their location in the power grid, a proprietary location algorithm based on a genetic algorithm was used. The controller of the ESU was carried out on the basis of the fuzzy logic, and the selection of parameters of ESU controllers was carried out with the use of an evolutionary algorithm. The objective function used in the authors' research was defined to limit total grid operation costs, which include costs related to failure to meet appropriate voltage level in the grid, costs related to the installation of ESU, costs of energy losses in the network across transmission elements, and costs related to overloading these elements.

The proposal referring to the selection and control of ESU was validated, based on a real LV grid model with quasidynamic daily load variations. In the analyzed grid, there were voltage problems resulting from the high load of the grid and energy production from PV sources. The voltage deviations were almost $\pm 20 \%$ from the reference value $V_{\text {ref. }}$. After the ESU application, the voltage deviations are limited to around $\pm 10 \%$ from the value $V_{\text {ref. }}$ Thus, it was shown that the correct choice of the location of ESU in the grid and the selection of the parameters of the controllers allow for ESU effective use, especially enabling to reach the voltage significantly closer to the reference value. The time of the calculation based on the proposed algorithm is short. The proposed integrated algorithm ensures the complex selection and control of the ESU, with taking into account the costs of the investment. Therefore, it can be a very useful universal tool, especially for power system operators, during consideration of ESU application.

Author Contributions: Conceptualization, S.C., Z.L. and R.M.; methodology, A.S.; software, A.S.; validation, A.S.; formal analysis, S.S., S.C. and R.M.; investigation, S.S.; resources, A.S. and S.S.; writing-original draft preparation, A.S., S.S. and S.C.; writing-review and editing, S.C. and R.M.; supervision, Z.L. and R.M. All authors have read and agree to the published version of the manuscript. 
Funding: This research was supported by Gdańsk University of Technology.

Conflicts of Interest: The authors declare no conflict of interest.

\section{Appendix A. Symbols}

a-auxiliary variable

$A_{\mathrm{t}}$ - energy consumed in a given node during the analyzed period

$b_{\mathrm{rt}}$-additional fee for failure to meet the required voltage level. In 2016 , the fee was $2.33(€ / \mathrm{h})$

$C$ - constant used to take positive value of $f$

$C_{\mathrm{t}}$-average price of electric energy. The assumed average price from 2016: $39.80(€ / \mathrm{MWh})$

$C_{\mathrm{TP}}$-unit price of a given type of a cable

$d$ - the number of successive generations in genetic algorithm

$d_{\text {max }}$-maximum generation number in genetic algorithm

$\mathrm{d} t$-15-min time step

$f$-objective function

$\mathbf{F}_{(\mathrm{k}, \mathrm{d})}$-matrix of the objective function in genetic algorithm

$\mathrm{F}_{\mathrm{t}}$ - group of results of the objective function calculations

$f_{\max }$ - the maximum value of the objective function

$g$ - the number of successive generations in evolutionary algorithm

$g_{\max }$ - the number of the generations in evolutionary algorithm

$i$ - $i$-th element (in general)

$j$-the number of the successive individual in the population in evolutionary algorithm

$j_{\max }-$ maximal numbers of individuals in the population in evolutionary algorithm

$K$ - cost of a given type of ESU

$k$-the number of successive individuals in the population in evolutionary algorithm

$k_{\max }$ - the maximal number of individuals in the population in evolutionary algorithm

$L-$ number of grid elements

$l_{\mathrm{c}}$ - cable length

$L_{\mathrm{oi}}$-load in the $i$-th element of the grid

$M$-value of the objective function to optimize the selection of parameters for the ESU controller

$M_{\min (n, g)}$ - minimal value in matrix of the objective function in evolutionary algorithm

$\mu P$-membership function for the active power of ESU

$\mu Q$ - membership function for the reactive power of ESU

$\mu_{\mathrm{V}}-$ membership function for the voltage $V_{\mathrm{i}}$ in the connection node of the ESU

$\mu_{\mathrm{SoC}}-$ membership function for the state of charge of ESU

$\mu_{\mathrm{I}}$-membership function for the line current

$n$ - the number of successive nodes

$\mathrm{N}$-number of nodes in the grid

$p_{1}$-component responsible for the cost of failure to meet the required level of voltage in the grid

$p_{2}$-component responsible for the cost of installing ESU in the grid

$p_{3}$-component responsible for power losses in the grid

$p_{4}$-component responsible for the cost of overloading the elements of the grid

$Q_{\text {ESU }}$-reactive output power of ESU

$Q_{\text {ref }}$-set/reference reactive power for ESU

$P_{\text {ESU }}$-active output power of ESU

$P_{\text {ref }}$-set/reference active power for ESU

I-load current in the grid element (e.g., in a cable line)

$I_{1}$ - the first auxiliary variable defining the shape of the membership function of $\mu_{\text {I_discharge_ability }}$

$I_{2}$ - the second auxiliary variable defining the shape of the membership function of $\mu_{\text {I_discharge_ability }}$

$I_{1^{\prime}}$ - the first auxiliary variable defining the shape of the membership function of $\mu_{\text {I_charge_ability }}$

$I_{2^{\prime}}$ - the second auxiliary variable defining the shape of the membership function of $\mu_{\text {I_charge_ability }}$

SoC-state of charge of ESU

$\mathrm{SoC}_{1}$ - auxiliary variable defining the shape of the membership function of $\mu_{\text {SoC_charged }}$

$\mathrm{SoC}^{\prime}{ }_{1}$-auxiliary variable defining the shape of the membership function of $\mu_{\text {SoC_discharged }}$ 
$T$-number of time steps $(T=96)$

$t$-discrete time

$t_{\mathrm{i}}$-number of steps (in analysis period) when the $i$-th element of the grid is overloaded

$t_{\mathrm{p}}$-expected period of the ESU operation (in days)

$t_{\mathrm{r}}$-duration of voltage failure

$V_{\mathrm{i}}$-voltage value in node $i$

$V_{\max }$ - the maximum permissible voltage in the grid adopted in evolutionary algorithm

$V_{\min }$ - minimum permissible voltage in the grid adopted in evolutionary algorithm

$V_{\min }$ - the first limit value of the minimum voltage in genetic algorithm

$V_{\operatorname{minB}}$ - the second limit value of the minimum voltage in genetic algorithm

$V_{\operatorname{maxA}}$ - the first limit value of the maximum voltage in genetic algorithm

$V_{\text {maxB }}$-the second limit value of the maximum voltage in genetic algorithm

$W_{\mathrm{n}}$-cost of installing the ESU in node $n$

$W_{\mathrm{UT}}$ - cost related to failure to keep the required voltage level in node $n$

$V_{\text {ref }}$-reference value of voltage

$\Delta P_{1}$-active power losses in the grid element $l_{\mathrm{i}}$

$\Delta V$-voltage deviation from the nominal value

$\Delta V_{\mathrm{i}}$-voltage deviation from the permissible value in $i$-th node

\section{References}

1. Sanduleac, M.; Albu, M.; Stanescu, D.; Stanescu, C. Grid Storage in LV Networks-An Appropriate Solution to Avoid Network Limitations in High RES Scenarios. In Proceedings of the 2019 International Conference on Electromechanical and Energy Systems (SIELMEN), Craiova, Romania, 9-11 October 2019; pp. 1-6.

2. Vai, V.; Alvarez-Herault, M.-C.; Raison, B.; Bun, L. Optimal Low-voltage Distribution Topology with Integration of PV and Storage for Rural Electrification in Developing Countries: A Case Study of Cambodia. J. Mod. Power Syst. Clean Energy 2020, 8, 531-539. [CrossRef]

3. Cieślik, S. Voltage control in low-voltage distribution grids with micro-sources (in Polish: Regulacja napięcia w sieciach dystrybucyjnych nn z mikroinstalacjami). In Proceedings of the Symposium, Współczesne Urządzenia Oraz Usługi Elektroenergetyczne, Telekomunikacyjne i Informatyczne', Poznań, Poland, 19-20 November 2014; pp. 24-27.

4. Tang, J.; Cai, D.; Yuan, C.; Qiu, Y.; Deng, X.; Huang, Y. Optimal configuration of battery energy storage systems using for rooftop residential photovoltaic to improve voltage profile of distributed network. J. Eng. 2019, 2019, 728-732. [CrossRef]

5. Zhang, Y.; Dong, Z.Y.; Luo, F.; Zheng, Y.; Meng, K.; Wong, K.P. Optimal allocation of battery energy storage systems in distribution networks with high wind power penetration. IET Renew. Power Gener. 2016, 10, 1105-1113. [CrossRef]

6. Nguyen, N.T.; Le, D.D.; Moshi, G.G.; Bovo, C.; Berizzi, A. Sensitivity analysis on locations of Energy Storage in power systems with wind integration. In Proceedings of the 15th International Conference on the Environment and Electrical Engineering (EEEIC), Rome, Italy, 10-13 June 2015; pp. 1115-1119.

7. Małkowski, R.; Jaskólski, M.; Pawlicki, W. Operation of the Hybrid Photovoltaic-Battery System on the Electricity Market-Simulation, Real-Time Tests and Cost Analysis. Energies 2020, 13, 1402. [CrossRef]

8. Pereira, C.O.; Cunha, V.C.; Ricciardi, T.R.; Torquato, R.; Freitas, W.; Riboldi, V.B.; Tuo, J. Pre-Installation Studies of a BESS in a Real LV Network with High PV Penetration. In Proceedings of the 2019 IEEE PES Innovative Smart Grid Technologies Conference-Latin America (ISGT Latin America), Gramado, Brazil, 15-18 September 2019; pp. 1-6.

9. Nduka, O.S.; Kunjumuhammed, L.P.; Pal, B.C.; Majumdar, A.; Yu, Y.; Maiti, S.; Ahmadi, A.R. Field Trial of Coordinated Control of PV and Energy Storage Units and Analysis of Power Quality Measurements. IEEE Access 2019, 8, 1962-1974. [CrossRef]

10. Zidar, M.; Georgilakis, P.S.; Hatziargyriou, N.D.; Capuder, T.; Škrlec, D. Review of energy storage allocation in power distribution networks: Applications, methods and future research. IET Gener. Transm. Distrib. 2016, 10, 645-652. [CrossRef]

11. Wasiak, I.; Pawelek, R.; Mienski, R. Energy storage application in low-voltage microgrids for energy management and power quality improvement. IET Gener. Transm. Distrib. 2014, 8, 463-472. [CrossRef] 
12. Swift-Hook, D. Wind energy really is the last to be stored and solar energy cannot be stored economically. Renew. Energy 2013, 50, 971-976. [CrossRef]

13. Venu, C.; Riffonneau, Y.; Bacha, S.; Baghzouz, Y. Battery storage system sizing in distribution feeders with distributed photovoltaic systems. In Proceedings of the 2009 IEEE Bucharest PowerTech, Bucharest, Romania, 28 June-2 July 2009; pp. 1-5.

14. Kaldellis, J.K.; Zafirakis, D.; Kondili, E. Optimum sizing of photovoltaic-energy storage systems for autonomous small islands. Int. J. Electr. Power Energy Syst. 2010, 32, 24-36. [CrossRef]

15. Makarov, Y.V.; Du, P.; Kintner-Meyer, M.C.; Jin, C.; Illian, H.F. Sizing energy storage to accommodate high penetration of variable energy resources. IEEE Trans. Sustain. Energy 2012, 3, 34-40. [CrossRef]

16. Marra, F.; Yang, G.; Traeholt, C.; Østergaard, J.; Larsen, E. A decentralized storage strategy for residential feeders with photovoltaics. IEEE Trans. Smart Grid 2014, 5, 974-981. [CrossRef]

17. Wogrin, S.; Gayme, D.F. Optimizing storage siting, sizing, and technology portfolios in transmissionconstrained networks. IEEE Trans. Power Syst. 2015, 30, 3304-3313. [CrossRef]

18. Pandžić, H.; Wang, Y.; Qiu, T.; Dvorkin, Y.; Kirschen, D.S. Near-optimal method for siting and sizing of distributed storage in a transmission network. IEEE Trans. Power Syst. 2015, 30, 2288-2300. [CrossRef]

19. Fernández-Blanco, R.; Dvorkin, Y.; Xu, B.; Wang, Y.; Kirschen, D.S. Optimal energy storage siting and sizing: A WECC case study. IEEE Trans. Sustain. Energy 2017, 8, 733-743. [CrossRef]

20. Bose, S.; Gayme, D.F.; Topcu, U.; Chandy, K.M. Optimal placement of energy storage in the grid. In Proceedings of the 2012 IEEE 51st IEEE Conference on Decision and Control (CDC), Grand Wailea Maui, HI, USA, 10-13 December 2012; pp. 5605-5612.

21. Giannitrapani, A.; Paoletti, S.; Vicino, A.; Zarrilli, D. Algorithms for placement and sizing of energy storage systems in low voltage networks. In Proceedings of the 2015 54th IEEE Conference on Decision and Control (CDC), Osaka, Japan, 15-18 December 2015; pp. 3945-3950.

22. Torchio, M.; Magni, L.; Raimondo, D.M. A mixed integer SDP approach for the optimal placement of energy storage devices in power grids with renewable penetration. In Proceedings of the American Control Conference (ACC), Chicago, IL, USA, 1-3 July 2015; pp. 3892-3897.

23. Nick, M.; Cherkaoui, R.; Paolone, M. Optimal siting and sizing of distributed energy storage systems via alternating direction method of multipliers. Int. J. Electr. Power Energy Syst. 2015, 72, 33-39. [CrossRef]

24. Zidar, M.; Capuder, T.; Georgilakis, P.S.; Škrlec, D. Convex AC optimal power flow method for definition of size and location of battery storage systems in the distribution grid. In Proceedings of the Ninth Conference on Sustainable Development of Energy, Water and Environment System-SDEWES, Zagreb, Croatia, 20-27 September 2014; pp. 1-23.

25. Nick, M.; Cherkaoui, R.; Paolone, M. Optimal allocation of dispersed energy storage systems in active distribution networks for energy balance and grid support. IEEE Trans. Power Syst. 2014, 29, 2300-2310. [CrossRef]

26. Lee, T.-Y.; Chen, N. Determination of optimal contract capacities and optimal sizes of battery energy storage systems for time-of-use rates industrial customers. IEEE Trans. Energy Convers. 1995, 10, 562-568.

27. Oh, H. Optimal planning to include storage devices in power systems. IEEE Trans. Power Syst. 2011, 26, 1118-1128. [CrossRef]

28. Nazaripouya, H.; Wang, Y.; Chu, P.; Pota, H.R.; Gadh, R. Optimal sizing and placement of battery energy storage in distribution system based on solar size for voltage regulation. In Proceedings of the 2015 IEEE Power \& Energy Society General Meeting, Denver, CO, USA, 26-30 July 2015; pp. 1-5.

29. Ma, Y.; Abad, M.S.S.; Azuatalam, D.; Verbic, G.; Chapman, A. Impacts of community and distributed energy storage systems on unbalanced low voltage networks. In Proceedings of the 2017 Australasian Universities Power Engineering Conference (AUPEC), Melbourne, Australia, 19-22 November 2017; pp. 1-6.

30. Ghofrani, M.; Arabali, A.; Etezadi-Amoli, M.; Fadali, M.S. A framework for optimal placement of energy storage units within a power system with high wind penetration. IEEE Trans. Sustain. Energy 2013, 4, 434-442. [CrossRef]

31. Celli, G.; Mocci, S.; Pilo, F.; Loddo, M. Optimal integration of energy storage in distribution networks. In Proceedings of the 2009 IEEE Bucharest PowerTech, Bucharest, Romania, 28 June-2 July 2009; pp. 1-7.

32. Gonçalves, J.; Neves, L.; Martins, A.G. Multiobjective Methodology for Assessing the Location of Distributed Electric Energy Storage. In Proceedings of the European Conference on the Applications of Evolutionary Computation, Copenhagen, Denmark, 8-10 April 2015; pp. 227-238. 
33. Qing, Z.; Nanhua, Y.; Xiaoping, Z.; You, Y.; Liu, D. Optimal siting \& sizing of battery energy storage system in active distribution network. In Proceedings of the Innovative Smart Grid Technologies Europe (ISGT EUROPE), Lyngby, Denmark, 6-9 October 2013; pp. 1-5.

34. Jamian, J.J.; Mustafa, M.W.; Mokhlis, H.; Baharudin, M.A. Simulation study on optimal placement and sizing of Battery Switching Station units using Artificial Bee Colony algorithm. Int. J. Electr. Power Energy Syst. 2014, 55, 592-601. [CrossRef]

35. Dvijotham, K.; Backhaus, S.; Chertkov, M. Operations-based planning for placement and sizing of energy storage in a grid with a high penetration of renewables. arXiv 2011, arXiv11071382.

36. Bahmani-Firouzi, B.; Azizipanah-Abarghooee, R. Optimal sizing of battery energy storage for micro-grid operation management using a new improved bat algorithm. Int. J. Electr. Power Energy Syst. 2014, 56, 42-54. [CrossRef]

37. Gantz, J.M.; Amin, S.M.; Giacomoni, A.M. Optimal mix and placement of energy storage systems in power distribution networks for reduced outage costs. In Proceedings of the 2012 IEEE Energy Conversion Congress and Exposition (ECCE), Raleigh, NC, USA, 15-20 September 2012; pp. 2447-2453.

38. Wen, S.; Lan, H.; Fu, Q.; David, C.Y.; Zhang, L. Economic allocation for energy storage system considering wind power distribution. IEEE Trans. Power Syst. 2015, 30, 644-652. [CrossRef]

39. Barnes, A.K.; Balda, J.C. Placement of distributed energy storage via multidimensional scaling and clustering. In Proceedings of the International Conference on Renewable Energy Research and Application (ICRERA), Milwaukee, WI, USA, 19-22 October 2014; pp. 69-74.

40. Barnes, A.K.; Balda, J.C.; Escobar-Mejia, A.; Geurin, S.O. Placement of energy storage coordinated with smart PV inverters. In Proceedings of the Innovative Smart Grid Technologies (ISGT), Washington, DC, USA, 16-20 January 2012; pp. 1-7.

41. Giannitrapani, A.; Paoletti, S.; Vicino, A.; Zarrilli, D. Optimal allocation of energy storage systems for voltage control in LV distribution networks. IEEE Trans. Smart Grid 2017, 8, 2859-2870. [CrossRef]

42. Marra, F.; Fawzy, Y.T.; Bulo, T.; Blazic, B. Energy storage options for voltage support in low-voltage grids with high penetration of photovoltaic. In Proceedings of the Innovative Smart Grid Technologies (ISGT Europe), Berlin, Germany, 14-17 October 2012; pp. 1-7.

43. Karanki, S.B.; Xu, D.; Venkatesh, B.; Singh, B.N. Optimal location of battery energy storage systems in power distribution network for integrating renewable energy sources. In Proceedings of the Energy Conversion Congress and Exposition (ECCE), Denver, CO, USA, 15-19 September 2013; pp. 4553-4558.

44. Liu, Y.J.; Chang, G.W.; Hsu, L.Y.; Jen, K.K.; Chung, C.S.; Chen, J.H. Modeling and simulations of the low-voltage distribution system integrated with energy storage systems in Kinmen Island. In Proceedings of the TENCON Conference, Macao, China, 1-4 November 2015; pp. 1-5.

45. Brenna, M.; De Berardinis, E.; Carpini, L.D.; Foiadelli, F.; Paulon, P.; Petroni, P.; Sapienza, G.; Scrosati, G.; Zaninelli, D. Automatic distributed voltage control algorithm in smart grids applications. IEEE Trans. Smart Grid 2013, 4, 877-885. [CrossRef]

46. Lubosny, Z.; Bialek, J.W. Supervisory control of a wind farm. IEEE Trans. Power Syst. 2007, 22, 985-994. [CrossRef]

47. Brekken, T.K.; Yokochi, A.; Von Jouanne, A.; Yen, Z.Z.; Hapke, H.M.; Halamay, D.A. Optimal energy storage sizing and control for wind power applications. IEEE Trans. Sustain. Energy 2011, 2, 69-77. [CrossRef]

48. Chaouachi, A.; Kamel, R.M.; Andoulsi, R.; Nagasaka, K. Multiobjective intelligent energy management for a microgrid. IEEE Trans. Ind. Electron. 2013, 60, 1688-1699. [CrossRef]

49. Haessig, P.; Ahmed, H.B.; Multon, B. Energy storage control with aging limitation. In Proceedings of the 2015 IEEE Eindhoven PowerTech, Eindhoven, The Netherlands, 29 June-2 July 2015; pp. 1-6.

50. Zhao, B.; Zhang, X.; Chen, J.; Wang, C.; Guo, L. Operation optimization of standalone microgrids considering lifetime characteristics of battery energy storage system. IEEE Trans. Sustain. Energy 2013, 4, 934-943. [CrossRef]

51. Dzionk, A.; Szultka, S. Methods of energy storages placement in low voltage power network. Autom. Elektr. Zaklócenia 2016, 7, 16-21. [CrossRef]

52. Szultka, A.; Malkowski, R. Selection of optimal location and rated power of capacitor banks in distribution network using genetic algorithm. In Proceedings of the 18th International Scientific Conference Electric Power Engineering (EPE), Kouty nad Desnou, Czech Republic, 17-19 May 2017; pp. 1-6.

53. Available online: https://www.ure.gov.pl/pl/urzad/informacje-ogolne/komunikaty-prezesa-ure/6695, Informacja-nr-452016.html (accessed on 18 December 2020). 
54. INDUSTRY BULLETIN URE-Electricity. In 'BIULETYN BRANŻOWY URE-Energia Elektryczna; no. 187 (2213); Urząd Regulacji Energetyki: Warszawa, Poland, 2016. (In Polish)

55. Battery Storage Solution with Fronius GEN24 Plus and BYD Battery-Box, Premium HVS/HVM; Fronius: Wels, Austria, 2020.

56. Czapp, S.; Szultka, S.; Ratkowski, F.; Tomaszewski, A. Risk of power cables insulation failure due to the thermal effect of solar radiation. Eksploat. Niezawodn. 2020, 22, 232-240. [CrossRef]

57. Amamra, S.-A.; Francois, B.; Lugaro, J. Day-ahead primary power reserve planning and day-D primary frequency control of a Li-ion battery. In Proceedings of the 2015 IEEE Eindhoven PowerTech, Eindhoven, The Netherlands, 29 June-2 July 2015; pp. 1-5.

Publisher's Note: MDPI stays neutral with regard to jurisdictional claims in published maps and institutional affiliations.

(C) 2020 by the authors. Licensee MDPI, Basel, Switzerland. This article is an open access article distributed under the terms and conditions of the Creative Commons Attribution (CC BY) license (http://creativecommons.org/licenses/by/4.0/). 